\title{
Paramagnetic NMR of phenolic oxime copper complexes - a joint experimental and density functional study
}

Michael Bühl, ${ }^{*[a]}$ Sharon E. Ashbrook, ${ }^{*[a]}$ Daniel M. Dawson, ${ }^{[a]}$ Rachel A. Doyle, ${ }^{[a]}$ Peter Hrobárik, ${ }^{[b]}$ Martin Kaupp, ${ }^{[b]}$ lain A. Smellie ${ }^{[a]}$

[a]University of St Andrews, School of Chemistry and Centre of Magnetic Resonance, North Haugh, St Andrews, Fife, KY16 9ST, Scotland, United Kingdom, email buehl@standrews.ac.uk, sema@st-andrews.ac.uk

${ }^{[b]}$ Technische Universität Berlin, Institut für Chemie, Strasse des 17. Juni 135, D-10623 Berlin, Germany

\begin{abstract}
${ }^{1} \mathrm{H}$ and ${ }^{13} \mathrm{C}$ pNMR properties of bis(salicylaldoximato)copper(II) were studied in the solid state using magic-angle-spinning NMR spectroscopy and, for the isolated complex and selected oligomers, using density-functional theory at the PBE0-1/3// PBE0-D3 level. Large paramagnetic shifts are observed, up to $\delta\left({ }^{1} \mathrm{H}\right)=272 \mathrm{ppm}$ and $\delta\left({ }^{13} \mathrm{C}\right)=1006 \mathrm{ppm}($ at $298 \mathrm{~K})$, which are rationalised through spin delocalisation from the metal onto the organic ligand and the resulting contact shifts arising from hyperfine coupling. The observed shift ranges are best reproduced computationally using exchange-correlation functionals with a high fraction of exact exchange (such as PBE0-1/3). Through a combination of experimental techniques and first-principles computation, a near-complete assignment of the observed signals is possible. Intermolecular effects on the pNMR shifts, modelled computationally in the dimers and trimers through effective decoupling between the local spins via A-tensor and total spin rescaling in the pNMR expression, are indicated to be small. Addition of electron-donating substituents and benzannelation of the organic ligand is predicted computationally to induce notable changes in the NMR signal pattern, suggesting that pNMR spectroscopy can be a sensitive probe for the spin distribution in paramagnetic phenolic oxime copper complexes.
\end{abstract}




\section{Introduction}

Hydrometallurgy, ${ }^{1}$ the extraction of metals from ores using aqueous chemical processes, is an important alternative to energy-intensive techniques involving smelting. ${ }^{2}$ Bespoke extractants are used on a large scale to separate and concentrate a variety of metals. In this respect, phenolic oximes are notable for their high affinity and selectivity toward copper, as they form very stable $\mathrm{Cu}$ (II) complexes that can be subject to liquid-liquid extraction, separation, and purification. Their ease of preparation and use also makes such oximes excellent targets for undergraduate laboratory courses. ${ }^{3}$

The complexes usually crystallise readily, and numerous structures have been characterised by X-ray crystallography. ${ }^{4}$ Clearly there are attractive intermolecular interactions between the complexes that can be tuned through appropriate substituent patterns for tailoring the solvation properties, with $\pi$-stacking between the aromatic moieties, arguably, the most important factor modulating or even governing these interactions. $\mathrm{Cu}$ (II) complexes are paramagnetic, which gives rise to the question if communication between the spins on different molecules contribute to the interaction. The metal centres in the solids are usually too far apart for direct or indirect exchange coupling, but it is unclear to what extent spin delocalisation onto the organic ligands occurs, which might in turn modulate any intermolecular interaction. Significant spin density on $\mathrm{H}$ and $\mathrm{N}$ atoms has been detected through EPR spectroscopy in solution and in the solid state, ${ }^{5}$ but in the absence of ${ }^{13} \mathrm{C}$ enriched samples, the precise spin distributions over the organic backbone are unknown. We now present an experimental and computational ${ }^{1} \mathrm{H}$ and ${ }^{13} \mathrm{C}$ solid-state NMR study of phenolic oxime copper(II) complexes at natural abundance in order to fill that gap.

NMR is an ideal technique to probe the local structure and short-range order or disorder in solid materials. While applications to diamagnetic solids are becoming more and more routine (at least for "benign" nuclei with high sensitivity and/or low or vanishing quadrupole moment), acquisition of NMR spectra for paramagnetic materials is still a challenge.

Advances in instrumentation (such as very fast magic-angle spinning) are beginning to make more and more classes of paramagnetic compounds amenable to study by solid-state NMR spectroscopy, including metalloproteins, ${ }^{6}$ smaller complexes, ${ }^{7}$ infinitely-connected metalorganic frameworks, ${ }^{8}$ and dense oxides. ${ }^{9}$ However, the assignment of individual resonances to specific chemical or crystallographic sites can still be a formidable task and may even require laborious syntheses for site-specific isotope labelling.

It is highly desirable to confirm, and eventually to make, such assignments based on reliable quantum-chemical computation of the salient NMR parameters, in particular isotropic shifts. Such calculations have proven very useful during assignment and interpretation of the multinuclear NMR spectra of diamagnetic materials. ${ }^{10,11}$ However, application of such computations to paramagnetic species is a big challenge. The first quantum-chemical methods to calculate paramagnetic NMR (pNMR) properties that went beyond the pure contact shifts were only devised in the early $2000 \mathrm{~s}^{12,13}$ and, even though refinements and further developments have been made since then, ${ }^{14,15,16,17}$ pNMR calculations remain far from routine.$^{18}$ Extension of the present computational techniques to pNMR properties of infinite periodic solids is in its infancy ${ }^{9,19}$ and is probably one of the final frontiers of computational NMR spectroscopy. As a further step toward that goal, we present a computational pNMR study alongside experimental measurements on phenolic oxime copper complexes, calling special attention to intermolecular effects on the pNMR chemical 
shifts. Such effects are shown to be relatively small, but the calculations prove instrumental for guiding the assignments and for prediction and future study of substituent effects.

\section{Results and Discussion}

The main target of this study is the bis(salicylaldoximato)copper(II) complex (1, Figure 1). The first X-ray crystallographic characterisation was published in $1964,{ }^{20}$ but a number of alternate refinements or polymorphs have been reported since. ${ }^{21}$ We will first describe the ${ }^{1} \mathrm{H}$ and ${ }^{13} \mathrm{C}$ NMR-spectroscopic characterisation of $\mathbf{1}$, followed by a discussion of the computed pNMR shifts. We will then comment on the assignments and, finally, discuss substituent effects in selected derivatives.

)

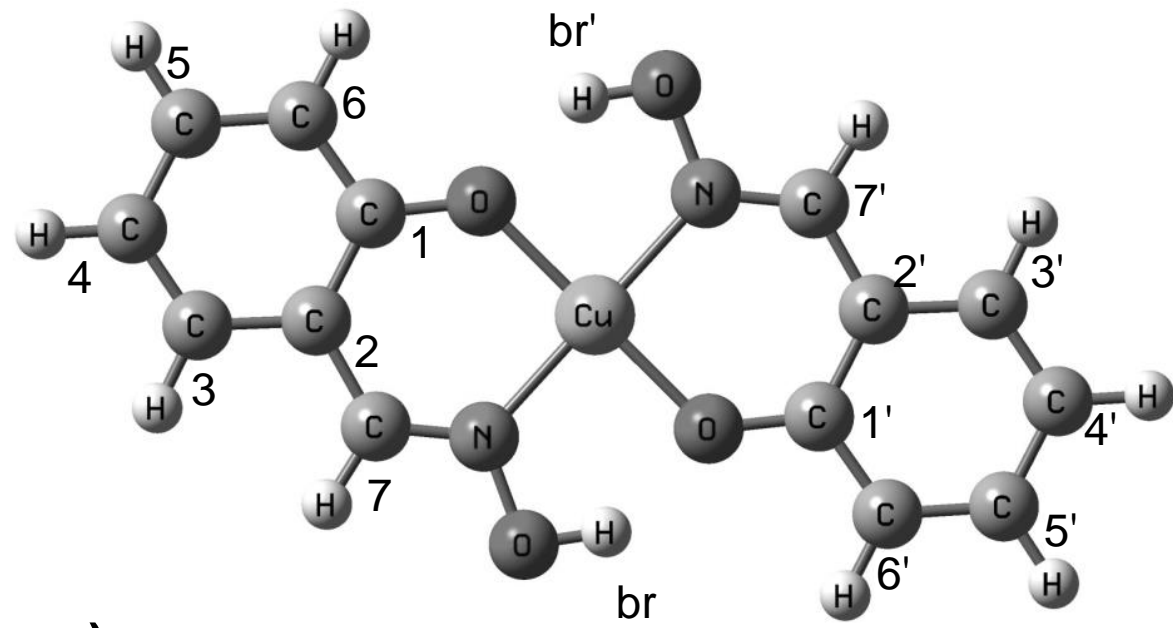

a)
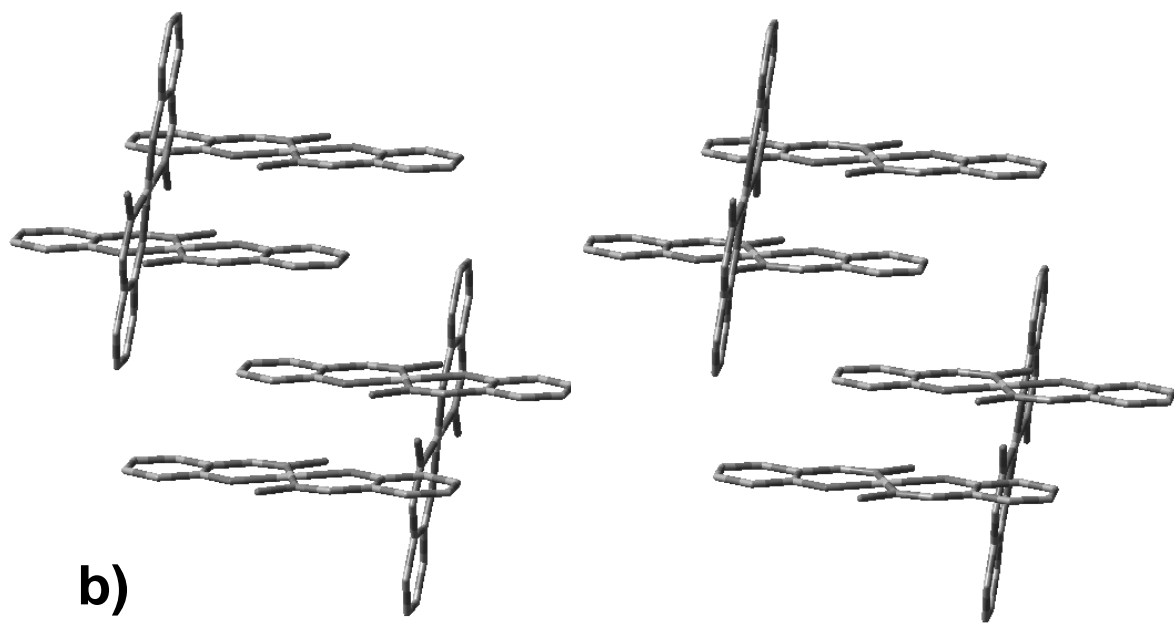

Figure 1: a) Structure of complex 1 with atom numbering; b) packing in the solid (from reference 21; stereoview). 


\section{NMR Experiments}

The ${ }^{1} \mathrm{H}$ MAS NMR spectrum of $\mathbf{1}$ (at $298 \mathrm{~K}$ ) is shown in Figure 2(a), and contains resonances at 272, 26.0, 22.7, 5.5 and $-5.4 \mathrm{ppm}$. Variable-temperature experiments over the range 278-338 $\mathrm{K}$ (shown in Figure 2(b)) show that, as might be expected, the more unusual isotropic shifts are the most temperature dependent. Figure 2(c) shows plots of ${ }^{1} \mathrm{H}$ $\delta_{\text {iso }}$ against $1000 / T$, with corresponding lines of best fit and regression coefficients $\left(R^{2}\right)$. The linear relationship expected for the "high-temperature" paramagnetic regime is observed in all cases, except the resonance at $5.5 \mathrm{ppm}$, whose position is essentially independent of temperature (to within $\sim 0.1 \mathrm{ppm}$ over the entire temperature range).

In addition to the unusual shifts, three of the observed ${ }^{1} \mathrm{H}$ resonances have reasonably large shift anisotropies (defined by the span $\left(\Omega=\delta_{11}-\delta_{33}\right)$ ). By far the largest is for the resonance at $22.6 \mathrm{ppm}$, which has $\Omega \approx 326 \mathrm{ppm}$, leading to intense spinning sidebands even with the rapid MAS rate $(37.5 \mathrm{kHz})$ used in the experiment. The other resonances have anisotropies that can be estimated in a "slow" MAS experiment (shown in Figure S1 in the electronic supporting information, ESI). The slowest MAS rate that could practically be used was 16 $\mathrm{kHz}$, to avoid overlap of spinning sidebands. In addition, at slower MAS rates, the line broadening from the ${ }^{1} \mathrm{H}$ homonuclear dipolar interaction begins to affect the spectral resolution. Table 1 summarises the NMR parameters for the $\mathrm{H}$ species observed.

a

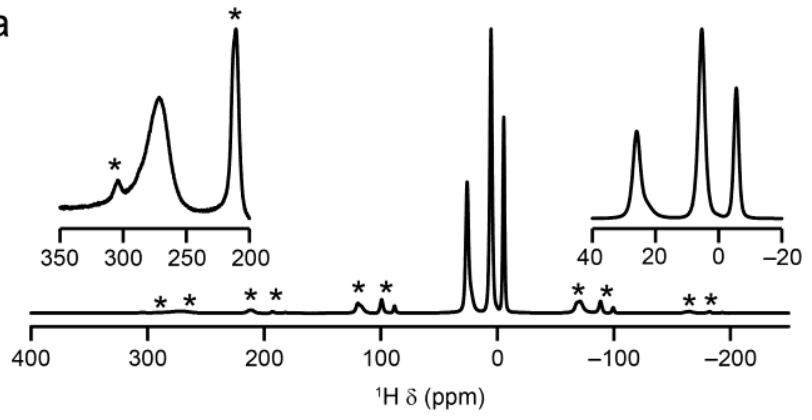

b

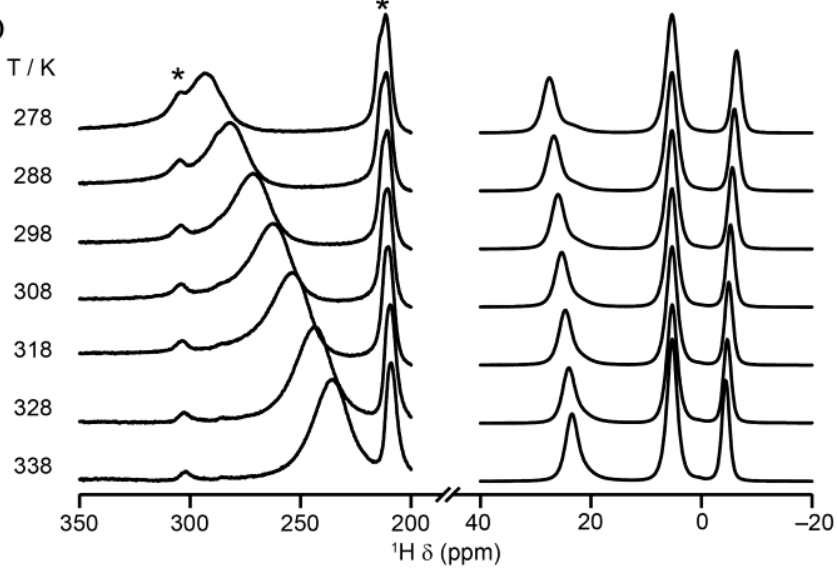

$\mathrm{C}$

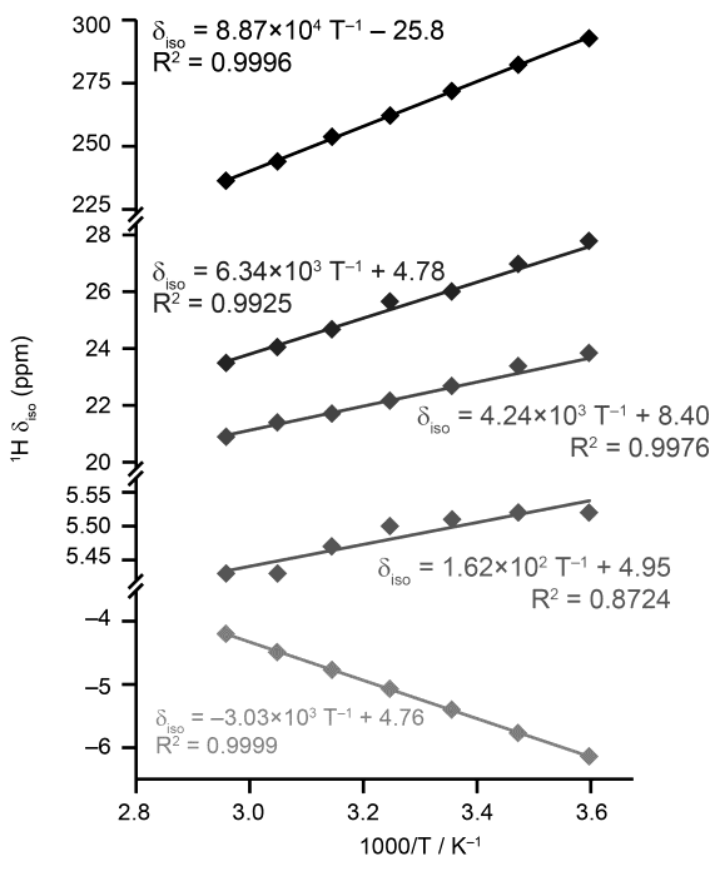

Figure 2. (a) ${ }^{1} \mathrm{H}(9.4 \mathrm{~T}, 298 \mathrm{~K}, 37.5 \mathrm{kHz}$ MAS) NMR spectrum of 1 (relative to TMS), with insets showing expansions of the isotropic resonances and spinning sidebands indicated with asterisks $\left({ }^{*}\right)$. (b) Variable-temperature ${ }^{1} \mathrm{H}(9.4 \mathrm{~T}, 37.5 \mathrm{kHz}$ MAS) NMR spectra of 1, where only the isotropic regions are shown (* indicates spinning sidebands of the resonances at 22.6 and $5.5 \mathrm{ppm}$ ). (c) Plots of the variation in isotropic ${ }^{1} \mathrm{H}$ peak position as a function of $1000 / T$. The lines of best fit and their equations and regression coefficients $\left(R^{2}\right)$ are given. 
Table 1. ${ }^{1} \mathrm{H}$ NMR parameters for 1 at $298 \mathrm{~K}$, and the temperature dependence of $\delta_{\text {iso. }}$. The $\mathrm{y}$ intercepts of the plots in Figure 2(c) are given by $\delta_{\text {iso }}$. The magnitude of the shift anisotropy is described by the span $(\Omega)$.

\begin{tabular}{cccc}
\hline$\delta_{\text {iso }}(\mathrm{ppm})$ & $\mathrm{d} \delta_{\text {iso }} / \mathrm{d}(1 / \mathrm{T})(\mathrm{ppm} \mathrm{K})$ & $\delta_{\text {iso }}{ }^{\infty}(\mathrm{ppm})$ & $\Omega(\mathrm{ppm})$ \\
\hline $272(2)$ & $8.87(8) \times 10^{4}$ & $-26(3)$ & $69(5)$ \\
$26.0(1)$ & $6.34(25) \times 10^{3}$ & $4.8(8)$ & $89(5)$ \\
$22.7(3)$ & $4.24(9) \times 10^{3}$ & $8.4(3)$ & $326(20)$ \\
$5.5(1)$ & $1.62(28) \times 10^{2}$ & $4.95(9)$ & $75(5)$ \\
$-5.4(1)$ & $-3.03(2) \times 10^{3}$ & $4.76(5)$ & $70(5)$ \\
\hline
\end{tabular}

The ${ }^{13} \mathrm{C}$ MAS NMR spectrum of $\mathbf{1}$ at $298 \mathrm{~K}$ is shown in Figure 3(a), and contains resonances at 1006, 963, 244, 148, 124, 118 and 79 ppm. The resonances at 1006 and 963 ppm are very broad and overlapping, and were originally thought to be a single resonance centred at $\sim 980 \mathrm{ppm}$ until the resonance was re-examined in light of the results of the DFT calculations (discussed below). Minor resonances (attributed to an unidentified impurity) are also observed at 85 and $143 \mathrm{ppm}$. Variable-temperature experiments over the range 278-338 K (shown in Figure 3(b)) show that the positions of all resonances are temperature dependent, with the more unusual isotropic shifts varying the most. Figure $3(\mathrm{c})$ shows plots ${ }^{{ }^{13}}{ }^{13} \mathrm{C} \delta_{\text {iso }}$ against 1000/T and their corresponding lines of best fit and $R^{2}$. As for ${ }^{1} \mathrm{H}$, a linear relationship is observed in all cases, although the plots for the two resonances at higher shift have lower regression coefficients owing to their overlap at higher temperature. Table 2 summarises the NMR parameters for the ${ }^{13} \mathrm{C}$ species observed.

Table 2. ${ }^{13} \mathrm{C}$ shifts for 1 at $298 \mathrm{~K}$, and the temperature dependence of $\delta_{\text {iso. }}$. The y intercepts of the plots in Figure $3(\mathrm{c})$ are given by $\delta_{\text {iso }}{ }^{\infty}$.

\begin{tabular}{ccc}
\hline$\delta_{\text {iso }}(\mathrm{ppm})$ & $\mathrm{d} \delta_{\text {iso }} / \mathrm{d}(1 / \mathrm{T})(\mathrm{ppm} \mathrm{K})$ & $\delta_{\text {iso }}(\mathrm{ppm})$ \\
\hline $1006(5)$ & $3.36(16) \times 10^{5}$ & $-115(51)$ \\
$963(5)$ & $2.62(26) \times 10^{5}$ & $90(84)$ \\
$244(1)$ & $3.89(4) \times 10^{4}$ & $114.0(14)$ \\
$148(1)$ & $2.97(13) \times 10^{3}$ & $137.4(4)$ \\
$124(1)$ & $-8.6(6) \times 10^{2}$ & $126.9(2)$ \\
$118(1)$ & $-1.33(5) \times 10^{3}$ & $122.3(1)$ \\
$79.0(5)$ & $-1.403(3) \times 10^{3}$ & $126.1(1)$ \\
\hline
\end{tabular}



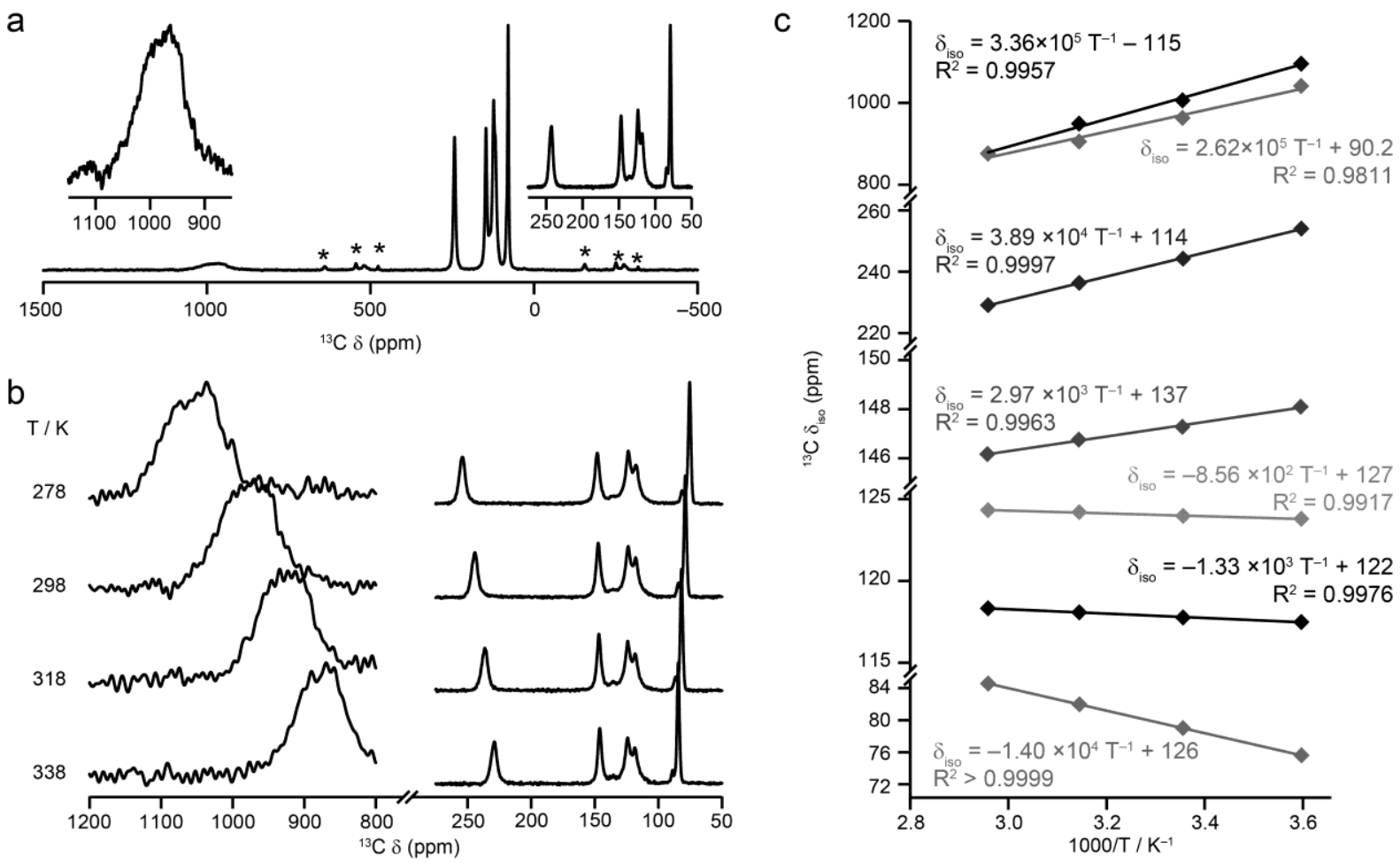

Figure 3. (a) ${ }^{13} \mathrm{C}(9.4 \mathrm{~T}, 298 \mathrm{~K}, 37.5 \mathrm{kHz}$ MAS) NMR spectrum of 1 (relative to TMS), with insets showing expansions of the isotropic resonances and spinning sidebands indicated with asterisks $\left({ }^{*}\right)$. (b) Variable-temperature ${ }^{13} \mathrm{C}(9.4 \mathrm{~T}, 37.5 \mathrm{kHz}$ MAS) NMR spectra of 1, where only the isotropic regions are shown. (c) Plots of the variation in isotropic ${ }^{13} \mathrm{C}$ peak position as a function of $1000 / T$. The lines of best fit and their equations and regression coefficients $\left(R^{2}\right)$ are given.

\section{DFT Computations}

To aid the spectral assignments, we performed DFT calculations of the pNMR shifts of 1 using a well-established methodology. ${ }^{13,14,15}$ Starting from the structure of one polymorph characterised by X-ray crystallography, ${ }^{21}$ a monomeric unit, a dimer ("slipped sandwich", cf. Figure 1(b), where two such units are shown), as well as a trimer were optimised. From the agreement between computed and observed distances (see Table S1 in the ESI), the PBE0D3 level of DFT was chosen for all further geometry optimisations. ${ }^{22}$

Initial pNMR shift calculations were performed using a variety of functionals, basis sets and other approximations. Results for a monomeric 1, which is a $3 d^{9}$ spin doublet are given in Table 3. Inclusion of the spin-orbit terms for the $A$ tensor of the lighter elements $\left(A_{\text {orb }}\right)$ has little effect, up to ca. $5 \mathrm{ppm}$ for ${ }^{13} \mathrm{C}$ (compare PBE/II and PBE/II(orb) entries in Table 3). As they increase the CPU time significantly (by a factor of 4 for this system) these spin-orbit terms were neglected in all subsequent calculations. 
Table 3: Computed ${ }^{1} \mathrm{H}$ and ${ }^{13} \mathrm{C}$ pNMR chemical shifts (in ppm relative to TMS at $298 \mathrm{~K}$ ) of pristine 1. ${ }^{a}$

\begin{tabular}{|c|c|c|c|c|c|c|}
\hline Nucleus & $\begin{array}{r}\mathrm{PBE} / \\
\mathrm{II}\end{array}$ & $\begin{array}{r}\text { PBE/ } \\
\text { II (orb) }{ }^{b}\end{array}$ & $\begin{array}{r}\text { PBE0/ } \\
\text { II }\end{array}$ & $\begin{array}{r}\text { PBE0/ } \\
\text { IIII }\end{array}$ & PBE0-1/3/ II & PBE0-1/3/ III \\
\hline $\mathrm{H} 7$ & 426.5 & 426.5 & 338.1 & 330.0 & 306.6 & 297.7 \\
\hline H5 & 57.9 & 57.7 & 38.6 & 38.6 & 35.0 & 35.2 \\
\hline $\mathrm{H}(\mathrm{br})$ & 57.1 & 55.2 & 34.4 & 37.1 & 31.7 & 34.6 \\
\hline $\mathrm{H} 3$ & 14.2 & 14.6 & 12.7 & 12.1 & 13.4 & 12.9 \\
\hline $\mathrm{H} 4$ & 10.6 & 10.6 & 7.8 & 8.0 & 6.5 & 6.8 \\
\hline $\mathrm{H} 6$ & -11.4 & -11.3 & -7.9 & -8.1 & -6.8 & -6.8 \\
\hline C6 & 1732.5 & 1737.9 & 1303.6 & 1271.8 & 1166.6 & 1183.2 \\
\hline C7 & 1696.7 & 1700.4 & 1113.7 & 1104.3 & 931.4 & 922.9 \\
\hline C5 & 344.4 & 343.2 & 262.2 & 264.6 & 235.3 & 237.6 \\
\hline C4 & 115.7 & 115.2 & 135.1 & 137.6 & 144.8 & 147.1 \\
\hline $\mathrm{C} 2$ & 233.9 & 235.8 & 133.0 & 137.9 & 132.4 & 137.8 \\
\hline C3 & 212.7 & 212.4 & 130.8 & 135.3 & 108.8 & 113.5 \\
\hline C1 & -15.3 & -19.5 & 52.1 & 75.8 & 79.2 & 99.3 \\
\hline
\end{tabular}

aSee Figure 1 for labelling scheme. ${ }^{b}$ Including $A_{\text {orb }}$ contributions in the $A$ tensor.

In contrast, the results are very sensitive to the exchange-correlation functional. It is clear from the observed (Tables 1 and 2) and computed (Table 3) chemical shift ranges that the contact term arising from spin density on the nucleus is dominating (see also below). As expected, the percentage of Hartree-Fock (HF) exchange is, thus, crucial. At the PBE level, much larger shift ranges are computed (ca. $450 \mathrm{ppm}$ and $1750 \mathrm{ppm}$ for ${ }^{1} \mathrm{H}$ and ${ }^{13} \mathrm{C}$, respectively) than observed (ca. $300 \mathrm{ppm}$ and $930 \mathrm{ppm}$, respectively). This finding is consistent with the tendency of GGA functionals to overestimate spin delocalisation from the metal to the ligand (an effect of the inherent self-interaction error in DFT). Inclusion of HF exchange reduces the extent of spin delocalisation and, hence, the computed shift ranges notably (to ca. $340 \mathrm{ppm}$ and $1200 \mathrm{ppm}$ for ${ }^{1} \mathrm{H}$ and ${ }^{13} \mathrm{C}$, respectively, with PBE0, and to ca. 300 and 1100 ppm, respectively, with PBE0-1/3). This spin delocalisation is illustrated by the computed total spin density (PBE/II level, Figure 4(b)), which essentially arises from the singly occupied HOMO (Figure 4(a)). This orbital has significant antibonding contributions between the $d_{x^{2}-y^{2}}$ orbital on $\mathrm{Cu}$ and $\sigma_{p}$-bonding orbitals, which are delocalised over large parts of the ligands. The contributions from the in-plane $p$-orbitals are clearly seen from the nodal planes passing through most of the lighter nuclei. It is the hybridisation through admixture of s-orbitals that gives rise to large hyperfine couplings at some of these nuclei, and, hence, to their large pNMR shifts. Among the $\mathrm{H}$ atoms it is the $\mathrm{H}$ atom at the imido moiety ( $\mathrm{H} 7$ in Figure 1(a)) that carries the highest spin density, in excellent agreement with recent low-temperature EPR results. ${ }^{5 b}$ As a consequence, this $\mathrm{H}$ atom is the one with the most pronounced downfield shift and can safely be assigned to the resonance observed at 272 ppm (Table 1). 
a)

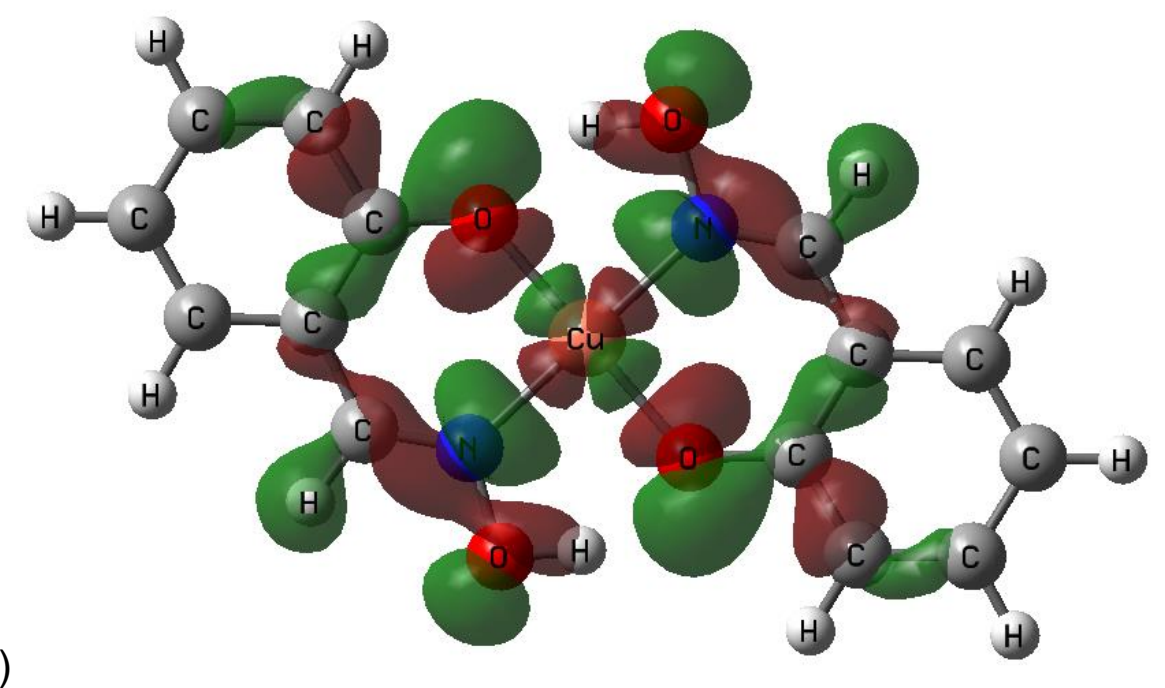

b)

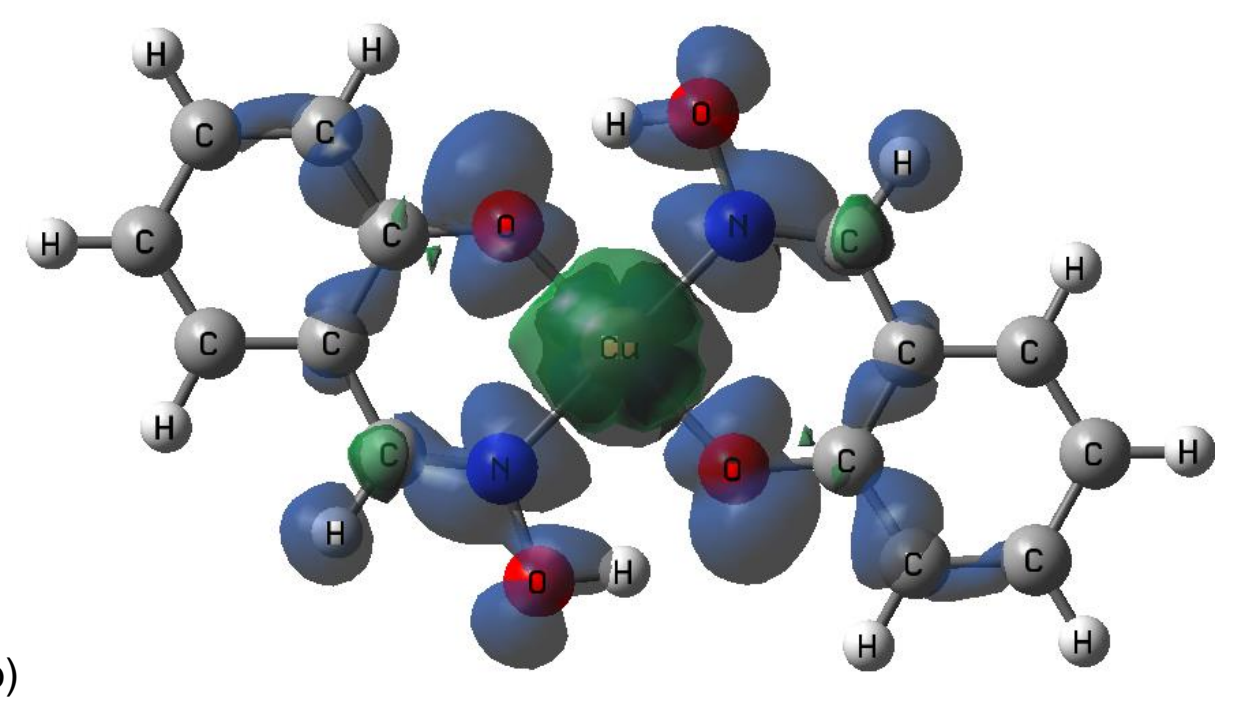

Figure 4: a) $\alpha-\mathrm{HOMO}$ and b) spin density of 1 (PBE/II//PBEO/AE1 ${ }^{(*)}$ level, isodensity surfaces at 0.02 a.u. for $\mathrm{MO}$ and 0.0004 a.u. for density); see Figure 1 (a) for atom numbers.

Among the $\mathrm{C}$ atoms, significant $\mathrm{s}$-spin density is accumulated on the imido $\mathrm{C}$ atom and the ortho- $\mathrm{C}$ atom opposite ( $\mathrm{C} 6$ and $\mathrm{C} 7$ in Figure 1(a)). Both have the highest computed shifts, approaching or exceeding 1000 ppm and appear very close to each other (within ca. 200 ppm at all levels of theory investigated). Initially the very broad signal in this region in the experimental spectrum had been assumed to be a single resonance (centered at $\sim 980$ ppm). However, closer inspection in the light of these calculated shifts revealed that the resonance can be decomposed into two signals separated by $\sim 40 \mathrm{ppm}$, in qualitative agreement with the computation.

Compared to the impact of the amount of HF exchange in the functional, the effect of increasing the basis set beyond IGLO-II for the ligand atoms is less pronounced. On going from IGLO-II to IGLO-III basis, the computed pNMR shifts change by up to ca. 8 ppm and 30 ppm for ${ }^{1} \mathrm{H}$ and ${ }^{13} \mathrm{C}$, respectively (Table 3 ). These maximum changes are observed for the nuclei experiencing the largest paramagnetic downfield shifts $(\mathrm{H} 7, \mathrm{C} 6$ and $\mathrm{C} 7)$; the results 
for other nuclei in the more "normal" (diamagnetic) chemical shift ranges are much less basis-set dependent.

As a first step toward modelling intermolecular effects, which may be important for the observed shifts in the solid, we performed computations for a "slipped-sandwich" dimer of complex 1 (in Figure 1(b) two such dimers can be discerned, one in the background at the top left, one in the foreground at the bottom right). ${ }^{23}$ The slippage is such that the aromatic ring of one molecular unit is close to the axial site of the Cu centre of the other (with $\mathrm{Cu} \cdots \mathrm{C}$ distances of ca. 3.6 $\AA$ indicating van-der-Waals contacts). Starting from the X-ray coordinates, this dimer structure was essentially maintained during optimisation (at the PBE0-D3 level, see Table S1). Finally, a third molecule was added to form a trimer in $C_{\text {i }}$ symmetry (Figure $\mathrm{S} 2$ in the ESI). As slight structural differences from the periodic structure began to appear for this trimer (e.g. a slightly too short Cu...Cu distance of $4.64 \AA$ as compared to $4.91 \AA$ in the solid), the trimer was reoptimised with the $\mathrm{Cu}$...Cu distance fixed to the value in the solid. ${ }^{24}$

The dimer and trimer were optimised assuming ferromagnetic coupling between the $\mathrm{Cu}$ centres (triplet and quartet states, respectively). The precise nature of this coupling in the full solid is unknown (see below). ${ }^{25}$ Based on the results for monomeric 1 discussed above, we will discuss primarily PBE0-1/3/ IGLO-II pNMR results, although selected PBE data are provided in the ESI.

To probe for the spatial proximity of a second molecule without possible complications from the coupling between spin centres, we performed initial pNMR calculations for a dimer in which one of the $\mathrm{Cu}$ centres was replaced with $\mathrm{Zn}$ (without reoptimisation), affording a simple doublet. By default, the gauge origin for the g-tensor evaluation is taken as the centre of electronic charge, which is identical with the Cu position in monomeric 1 , but at the centre of inversion in the dimer, i.e., off-centre with respect to each of the monomers. Two test calculations for the "Cu-Zn dimer" at the PBE0-1/3/ IGLO-II level using both choices for the gauge origin afforded virtually identical results (at most $0.1 \mathrm{ppm}$ difference for some ${ }^{13} \mathrm{C}$ nuclei, data not shown) so that ,subsequently, the centre of charge was used throughout.

In the solid the metal atoms reside on inversion centres so that both salicylaldoximate ligands are equivalent by symmetry. In a pristine dimer they are not, so that different shifts are computed for nuclei that are formally equivalent in experiment. In Table 4 we report the arithmetic average for such equivalent pairs, along with the individual differences for each of the resonances ( \pm values in parentheses).

For the "Cu-Zn dimer", these individual differences are small to modest (up to ca. $1.5 \mathrm{ppm}$ and $22 \mathrm{ppm}$ for ${ }^{1} \mathrm{H}$ and ${ }^{13} \mathrm{C}$, respectively), and the changes of the mean values from those in the pristine monomer are small for most nuclei (a few ppm), except for the most deshielded ${ }^{13} \mathrm{C}$ resonances around $\delta=1000 \mathrm{ppm}$, where changes of up to $30 \mathrm{ppm}$ are computed (compare entries for "pristine 1" and "dimer (M=Zn)" in Table 4). Similarly, small to modest changes are obtained for the trimer, where the central copper complex is sandwiched by two $\mathrm{Zn}$ moieties (again simply replacing the corresponding $\mathrm{Cu}$ atoms in the optimised structure, see "trimer ( $M=Z n)$ " entry in Table 4). 
Table 4: ${ }^{1} \mathrm{H}$ and ${ }^{13} \mathrm{C}$ pNMR isotropic shifts (in ppm relative to TMS at $298 \mathrm{~K}$ ) of 1 and its adducts with one $\mathrm{M}\left(\mathrm{C}_{7} \mathrm{H}_{6} \mathrm{NO}_{2}\right)_{2}$ moiety (dimer) or sandwiched by two of these (trimer), PBE0$1 / 3$ / IGLO-II level, doublet states.

\begin{tabular}{lrrrrr}
\hline Nucleus & $\begin{array}{rrrr}\text { pristine } \\
\mathbf{1}\end{array}$ & $\begin{array}{r}\text { dimer } \\
(\mathrm{M}=\mathrm{Zn})^{a}\end{array}$ & $\begin{array}{r}\text { dimer } \\
(\mathrm{M}=\mathrm{Cu})^{a, b}\end{array}$ & $\begin{array}{r}\text { trimer } \\
(\mathrm{M}=\mathrm{Zn})\end{array}$ & $\begin{array}{r}\text { trimer } \\
(\mathrm{M}=\mathrm{Cu})^{b}\end{array}$ \\
\hline $\mathrm{H} 7,7^{\prime}$ & 306.6 & $303.5( \pm 1.5)$ & $303.7( \pm 2.9)$. & 302.2 & 301.9 \\
$\mathrm{H} 5,5^{\prime}$ & 35.0 & $33.7( \pm 0.6)$ & $34.7( \pm 0.3)$ & 32.6 & 34.4 \\
$\mathrm{H}(\mathrm{br}, \mathrm{br})^{\prime}$ & 31.7 & $32.9( \pm 1.6)$ & $30.9( \pm 2.16)$ & 32.9 & 32.6 \\
$\mathrm{H} 3,3^{\prime}$ & 13.4 & $13.6( \pm 0.2)$ & $14.1( \pm 0.2)$ & 13.4 & 14.2 \\
$\mathrm{H} 4,4^{\prime}$ & 6.5 & $5.6( \pm 0.2)$ & $5.4( \pm 0.4)$ & 5.9 & 6.0 \\
$\mathrm{H} 6,6^{\prime}$ & -6.8 & $-7.1( \pm 0.7)$ & $-7.4( \pm 0.5)$ & -6.6 & -6.9 \\
\hline $\mathrm{C} 6,6^{\prime}$ & 1166.6 & $1142.1( \pm 7.9)$ & $1134.4( \pm 13.7)$ & 1127.6 & 1109.7 \\
$\mathrm{C} 7,7^{\prime}$ & 931.4 & $901.3( \pm 8.6)$ & $903.5( \pm 12.7)$ & 894.6 & 903.2 \\
$\mathrm{C} 5,5^{\prime}$ & 235.3 & $228.0( \pm 4.6)$ & $221.9( \pm 1.6)$ & 232.8 & 221.1 \\
$\mathrm{C} 4,4^{\prime}$ & 144.8 & $147.6( \pm 2.1)$ & $151.3( \pm 0.5)$ & 144.0 & 148.4 \\
$\mathrm{C} 2,2^{\prime}$ & 132.4 & $138.7( \pm 6.2)$ & $138.8( \pm 8.6)$ & 145.5 & 142.6 \\
$\mathrm{C} 3,3^{\prime}$ & 108.8 & $106.0( \pm 2.2)$ & $102.9( \pm 1.6)$ & 108.8 & 106.6 \\
$\mathrm{C} 1,1^{\prime}$ & 79.2 & $68.2( \pm 21.7)$ & $56.3( \pm 10.1)$ & 80.1 & 58.4 \\
\hline
\end{tabular}

${ }^{a}$ Mean value for the pair of nuclei indicated in the first column (in parentheses difference of each individual nucleus within the pair from this average). ${ }^{b} \sigma_{\text {orb }}, g$ and $A$ tensors taken from the high-spin calculation, $A$-tensors and pNMR shift expression rescaled to that of a doublet (see the text for details).

Effects from dia- or paramagnetic ring currents circulating around the metal centre or the aromatic rings of one monomer on the nuclei of others nearby can be probed by evaluating the orbital contributions to the shielding constant $\left(\sigma_{\text {iso(orb) }}\right)$ at those points in space around pristine 1 where the nuclei of the second molecule would be placed. Such anisotropy effects can be significant, e.g., for ${ }^{1} \mathrm{H}$ chemical shifts of hydride ligands directly bonded to heavier $\mathrm{d}$ or f-block elements, ${ }^{26}$ but are small in this case as the molecules are rather far apart

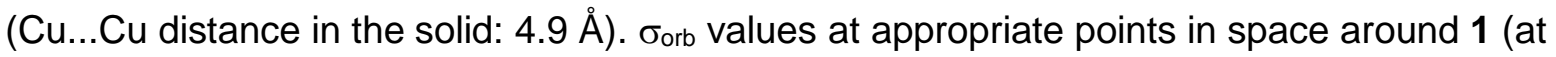
the "virtual" $\mathrm{C}$ and $\mathrm{H}$ positions of the nearest neighbour) are all less than $1 \mathrm{ppm} .{ }^{27} \mathrm{By}$ and large, the spin distribution within a molecular moiety appears to be perturbed little by the presence of neighboring diamagnetic complexes.

In contrast, much larger effects are predicted for the dimer with two ferromagneticallycoupled Cu centres. In particular, the more deshielded pNMR shifts are increased greatly by the presence of the second spin on the nearest neighbour: by ca. 100 and 300 ppm for $\mathrm{H} 7$ and C6, respectively (compare entries for 1 and $\mathrm{M}=\mathrm{Cu}$ in Tables S2 and S3). Adding a third molecule of 1 to form a centrosymmetric trimer in its high-spin state brings about similarly large shifts (compare entries for $\mathrm{M}=\mathrm{Cu}$ and trimer in Tables S2 and S3). Compared to the pristine monomer, such ferromagnetically-coupled oligomers, therefore, show strongly enhanced pNMR shifts in poor agreement with experiment (Tables 1 and 2). 
Zero-field splitting (ZFS) in these oligomers with total spin larger than $1 / 2$ is expected to be small because of the expected weak exchange coupling between the Cu centres. For strongly coupled spins located on the same metal centre, ZFS can be included in the pNMR expressions by modifications arising from the D-tensor. ${ }^{14}$ It is debatable if this methodology developed for high-spin metal centres can be applied to more distant ferromagnetically coupled spins. Tables S2 and S3 show that if it is applied, only very small effects on the final pNMR shifts are calculated, with maximum changes of ca. $3-4$ ppm for $\delta\left({ }^{1} \mathrm{H}\right)$ or $\delta\left({ }^{13} \mathrm{C}\right)$ (compare "M=Cu no ZFS" and "M=Cu with ZFS" entries in Tables S2 and S3). ${ }^{28}$ Similarly small effects from the D-tensor contributions are obtained for the high-spin trimer (results not shown) and are, therefore, neglected henceforth.

From the results for the high-spin cluster models it is apparent that the current theory of pNMR shifts cannot be applied to an aggregate of weakly spin-coupled subunits when this aggregate is to be treated as a high-spin supermolecule. The reason is quite simple: the expression for the $A$-tensor elements contains a factor $\left\langle\hat{S}_{z}\right\rangle^{-1},{ }^{29}$ that for the pNMR contributions to the magnetic shielding contains a factor $S(S+1) \cdot{ }^{12,14}$ Thus, the pNMR shifts diverge as more and more monomers are added with concomitant increase of the total spin. This is a consequence of the fact that the solid does not correspond to a ferromagnetically coupled state but likely exhibits a statistical distribution of local spins. As a pragmatic workaround, we calculated the pNMR shifts of these oligomers by treating them as simple doublets through manually setting the total spin to 0.5 in the pNMR expression and by rescaling the $A$ tensors from the high-spin calculation by multiplying all tensor elements by $2\left\langle\hat{S}_{z}\right\rangle$ (where $\hat{S}_{z}$ is the expectation value in the high-spin case, i.e., 1 and 1.5 for the triplet and quartet, respectively). ${ }^{30}$ In this way it is possible to effectively spin-decouple one monomer from the spin of its neighbors, forming an isolated doublet. The wavefunction and its associated primary response properties, namely $\sigma_{\text {orb }}, g$ and $A$ tensors (the latter encoding the spin distribution), can adjust to the presence of the neighbouring monomers, while the rescaling of the total spin and the $A$ tensors implies a spin-decoupled calculation of the pNMR shifts. In the limit of weakly-coupled monomers, as in our case (see below for a justification), we believe this is a reasonable approximation.

The resulting data for the dimer and trimer are included in Table 4 ( $M=C u$ entries). Compared to the zincated doublet models ( $M=Z n$ entries), the presence of the open-shell neighbours brings about some minor modifications of the pNMR shifts, but typically less than observed on going from the pristine monomer to the zincated models. While the computed ${ }^{1} \mathrm{H}$ shifts change only little with the environment, a somewhat larger sensitivity is apparent for the ${ }^{13} \mathrm{C}$ shifts. On going from the monomer to the trimer $(\mathrm{M}=\mathrm{Cu})$, the largest changes (between ca. 20 and 60 ppm) are obtained for C1, C6, C2 and C7, which have the highest spin density (see Figure 4(b)) and are closest to the neighbouring Cu centre. Importantly, no qualitative changes are brought about by these cluster models for the solid, i.e., the relative sequence of the shifts is maintained.

The pNMR shifts for the trimer in a doublet state were also computed, converging a suitable broken-symmetry (BS) wavefunction, where the spin on one of the terminal $\mathrm{Cu}\left(\mathrm{C}_{7} \mathrm{H}_{6} \mathrm{NO}_{2}\right)_{2}$ moieties has been flipped (denoted "BS $\downarrow \uparrow \uparrow "$ in Table S3). ${ }^{31}$ At the PBE0-1/3/ IGLO-II level, this BS state is slightly more stable than the high-spin quartet, but the preference for this antiferromagnetic coupling is very small, with a predicted Heisenberg exchange coupling constant $J$ of around $-0.3 \mathrm{~cm}^{-1} .^{32}$ This result fully justifies the "spin-decoupled" approach 
discussed above. The same result is found for a BS open-shell singlet state for the dimer. There are no paramagnetic NMR shifts for such a BS singlet, but its orbital contributions to

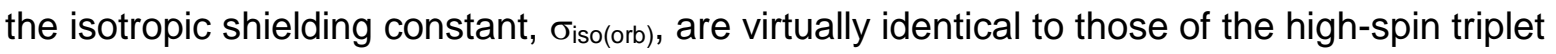
state (to within fractions of a ppm in all cases). Therefore, in all pNMR calculations for the trimer, the orbital contributions were taken from the high-spin quartet state. The pNMR shifts of the central moiety in the BS $\downarrow \uparrow \uparrow$ trimer are of the same order of magnitude as those of the monomer and the other oligomer models (Table 4). However, because the direct use of a BS-wavefunction with its huge spin contamination in property calculations without spinprojection procedures is ill-justified we will not discuss these results further.

For the nuclei with the most pronounced paramagnetic shifts, $\mathrm{H} 7, \mathrm{C} 1$ and $\mathrm{C} 6$, the shielding constants are broken down into the constituent contributions according to reference 14 (Table 5). As expected, it is the contact shift $\left(g_{\mathrm{e}} \cdot A_{\mathrm{FC}}\right)$ that is the dominant contribution. The data in Table 5 illustrate how, in particular for $\mathrm{C6}$, this contribution is modulated through the small changes of the hyperfine coupling constant $\left(A_{\text {iso }}\right)$ upon interaction with the neighbouring molecules. Deviations of the isotropic $g$-value from the corresponding freeelectron value modify the contact shifts further ( $\Delta g_{\mathrm{iso}} \cdot A_{\mathrm{FC}}$ contribution).

Table 5: EPR parameters and resulting contributions to the pNMR shielding tensor for selected nuclei in 1 and its $\left[\mathrm{M}\left(\mathrm{C}_{7} \mathrm{H}_{6} \mathrm{NO}_{2}\right)_{2} \cdot \mathrm{Cu}\left(\mathrm{C}_{7} \mathrm{H}_{6} \mathrm{NO}_{2}\right)_{2} \cdot \mathrm{M}\left(\mathrm{C}_{7} \mathrm{H}_{6} \mathrm{NO}_{2}\right)_{2}\right]$ trimer models, PBE0$1 / 3 /$ IGLO-II level ( $g$ is dimensionless, $A$ is in MHz and pNMR contributions are in ppm).

\begin{tabular}{lllll}
\hline Nucleus & Property & monomer & $\begin{array}{l}\text { trimer } \\
(\mathrm{M}=\mathrm{Zn})\end{array}$ & $\begin{array}{l}\text { trimer } \\
(\mathrm{M}=\mathrm{Cu})^{b}\end{array}$ \\
\hline $\mathrm{H} 7$ & $g_{\text {iso }}$ & 2.089635 & 2.094185 & 2.092923 \\
\hline & $\sigma_{\text {iso(orb) }}$ & 23.7 & 24.1 & 24.1 \\
& $A_{\text {iso }}$ & 10.86 & 10.66 & 10.65 \\
& $g_{\mathrm{e}} \cdot A_{\mathrm{FC}}$ & -286.8 & -282.4 & -282.3 \\
& $\Delta g_{\text {iso }} \cdot A_{\mathrm{FC}}$ & -12.5 & -13.0 & -12.8 \\
& $\Delta \mathbf{g}_{\text {aniso }} \cdot \mathbf{A}_{\text {dip }}{ }^{c}$ & 0.8 & 0.8 & 0.8 \\
\hline $\mathrm{C} 6$ & $\sigma_{\text {iso(orb) }}$ & 62.7 & 63.8 & 61.6 \\
& $A_{\text {iso }}$ & 9.49 & 9.11 & 8.91 \\
& $g_{\mathrm{e}} \cdot A_{\mathrm{FC}}$ & -998.2 & -959.8 & -939.3 \\
& $\Delta g_{\text {iso }} \cdot A_{\mathrm{FC}}$ & -43.5 & -44.0 & -42.5 \\
& $\Delta \mathbf{g}_{\text {aniso }} \cdot \mathbf{A}_{\text {dip }}{ }^{c}$ & 0.0 & 1.5 & -0.5 \\
\hline C1 & $\sigma_{\text {iso(orb) }}$ & 20.5 & 20.7 & 19.6 \\
& $A_{\text {iso }}$ & -0.79 & -0.76 & -0.98 \\
& $g_{\mathrm{e}} \cdot A_{\mathrm{FC}}$ & 81.1 & 80.1 & 103.5 \\
& $\Delta g_{\text {iso }} \cdot A_{\mathrm{FC}}$ & 3.5 & 3.7 & 4.7 \\
& $\Delta \mathbf{g}_{\text {aniso }} \cdot \mathbf{A}_{\text {dip }}{ }^{c}$ & 4.8 & 4.5 & 2.9 \\
\hline
\end{tabular}

${ }^{a}$ High-spin value (see text). ${ }^{b} A$-tensor and pNMR contributions scaled to $S=0.5$ (see text). ${ }^{c}$ One third of the trace.

For comparison with the observed tensor properties and temperature dependencies (Tables 1 and 2) of the experimental measurements the corresponding quantities have been computed for monomeric $\mathbf{1}$ and are given in Table 6. 
Table 6. Calculated ${ }^{1} \mathrm{H}$ and ${ }^{13} \mathrm{C}$ NMR parameters for 1 (PBE0-1/3/ IGLO-II level).

\begin{tabular}{ccccc}
\hline Site & $\delta_{\text {iso }}(\mathrm{ppm})^{a}$ & $\mathrm{~d} \delta_{\text {iso }} / \mathrm{d}(1 / \mathrm{T})(\mathrm{ppm} \mathrm{K})$ & $\delta_{\text {iso }}{ }^{\infty}(\mathrm{ppm})$ & $\Omega(\mathrm{ppm})^{a}$ \\
\hline H7 & 306.6 & $8.91 \times 10^{4}$ & 7.76 & 102 \\
H5 & 35.0 & $8.21 \times 10^{3}$ & 7.43 & 24 \\
$\mathrm{H}(\mathrm{br})$ & 31.7 & $6.30 \times 10^{3}$ & 10.6 & 349 \\
$\mathrm{H} 3$ & 13.4 & $1.84 \times 10^{3}$ & 7.22 & 19 \\
$\mathrm{H} 4$ & 6.5 & $-1.01 \times 10^{2}$ & 6.85 & 40 \\
$\mathrm{H} 6$ & -6.8 & $-4.13 \times 10^{3}$ & 7.03 & 95 \\
C6 & 1166.6 & $3.11 \times 10^{5}$ & 114.0 & 283 \\
C7 & 931.4 & $2.31 \times 10^{5}$ & 149.6 & 922 \\
C5 & 235.3 & $2.83 \times 10^{4}$ & 139.4 & 394 \\
C4 & 144.8 & $7.14 \times 10^{3}$ & 120.6 & 238 \\
C2 & 132.4 & $3.89 \times 10^{3}$ & 119.1 & 295 \\
C3 & 108.8 & $-9.25 \times 10^{3}$ & 140.1 & 255 \\
C1 & 79.2 & $-2.67 \times 10^{4}$ & 169.6 & 748 \\
\hline
\end{tabular}

${ }^{a}$ Calculated for $298 \mathrm{~K}$

\section{Spectral assignment}

Assignment of the spectra would be impossible (or at least very challenging and time consuming) without input from the DFT calculations. However, several discrepancies can immediately be seen between the calculated (Table 6) and experimental parameters (Tables 1 and 2), particularly for ${ }^{1} \mathrm{H}$, where there are no resonances observed at $13.4,35.0$ or 31.7 ppm, and none calculated to be at 26.0 or $22.7 \mathrm{ppm}$. Therefore, the calculations were used initially as a guide to help assign the spectra, but with experimental confirmation sought where practically possible. As preparing isotopically-enriched material is too expensive and time consuming (as well as requiring the development of new synthetic procedures), twodimensional NMR experiments were carried out to aid assignment. However, owing to the very fast nuclear relaxation in paramagnetic systems, the number and sophistication of the experiments available (and the range of information they can provide) is limited.

In this case, the most useful tool for experimental assignment proved to be ${ }^{1} \mathrm{H}-{ }^{13} \mathrm{C}$ heteronuclear correlation (HETCOR) spectra, using cross polarisation (CP) from ${ }^{1} \mathrm{H}$ as the means of magnetisation transfer. Although this experiment transfers magnetisation via the through-space dipolar interaction, by using a short (100 $\mu \mathrm{s}) \mathrm{CP}$ "contact time" , the transfer can be limited to short (essentially one-bond) distances, allowing only the observation of directly bonded $\mathrm{C}-\mathrm{H}$ pairs. The ${ }^{1} \mathrm{H}-{ }^{13} \mathrm{C}$ HETCOR spectrum of 1 is shown in Figure 5 (note that the spectrum had to be recorded with stepwise acquisition in both dimensions to enable efficient spin locking of all resonaces, and the figure presents a composite of four separate experiments). The cross-peak at $(963,272) \mathrm{ppm}$ is a reasonable match for $\mathrm{C} 7-\mathrm{H} 7$, predicted to be at $(931.4,306.6) \mathrm{ppm}$, the resonance at $(1021,-5.4) \mathrm{ppm}$ is a reasonable match for C6-H6, predicted to be at $(1166.6,-6.8) \mathrm{ppm}$, and the resonance at $(244,26.0) \mathrm{ppm}$ is a reasonable match for $\mathrm{C} 5-\mathrm{H} 5$ predicted to be at $(235.3,35.0) \mathrm{ppm}$. The only other intense resonances observed are at $(124,5.5)$ and $(118,5.5) \mathrm{ppm}$, and must correspond to C3-H3 and $\mathrm{C} 4-\mathrm{H} 4$, which are predicted to be at $(108.8,13.4)$ and $(144.8,6.5)$, respectively, despite the poor agreement between experiment and calculation for $\mathrm{H} 3$ and $\mathrm{C} 4$. However, it was shown in Figure 2(c) that the position of the ${ }^{1} \mathrm{H}$ resonance at $5.5 \mathrm{ppm}$ is essentially independent of temperature, indicating that the DFT calculations may have placed a small 
amount of spurious spin density on $\mathrm{H} 3$ and $\mathrm{H} 4$ when, in reality, these species appear to have essentially no hyperfine coupling. Indeed, as seen in Figure $3(\mathrm{c})$, the ${ }^{13} \mathrm{C}$ resonances correlated to the ${ }^{1} \mathrm{H}$ resonance at $5.5 \mathrm{ppm}$ also display the smallest temperature dependences observed for the ${ }^{13} \mathrm{C}$ spectrum, indicating smaller hyperfine couplings than calculated. The only other resonance observed in the HETCOR spectrum is at $(79,5.5) \mathrm{ppm}$, suggesting a quaternary $\mathrm{C}$ species spatially close to either $\mathrm{H} 3$ or $\mathrm{H} 4$. Figure $\mathrm{S} 3$ shows all of the through-space $\mathrm{H}-\mathrm{C}$ contacts under $3.5 \AA$, and Table S5 lists all $\mathrm{C}-\mathrm{H}$ contacts under $3.5 \AA$ (including intermolecular and intramolecular distances). The two quaternary $\mathrm{C}$ species are $\mathrm{C} 1$ and $\mathrm{C} 2$, and it can be seen that the shortest $\mathrm{C} 1-\mathrm{H} 3 / \mathrm{H} 4$ contact is $3.40 \AA$ to $\mathrm{H} 3$, whereas $\mathrm{C} 2$ is $2.17 \AA$ from $\mathrm{H} 3$ and also $3.43 \AA$ from $\mathrm{H} 4$. This would seem to suggest that the crosspeak from $\mathrm{C} 2-\mathrm{H} 3$ should be the most intense of these three possible correlations when the contact time is short, thus assigning the resonances at 79 and 148 ppm to C2 and C1, respectively. However, this contradicts the calculations, which predict exactly the opposite sequence (final estimates ca. 148 and 75 ppm for C2 and C1, respectively, see below).

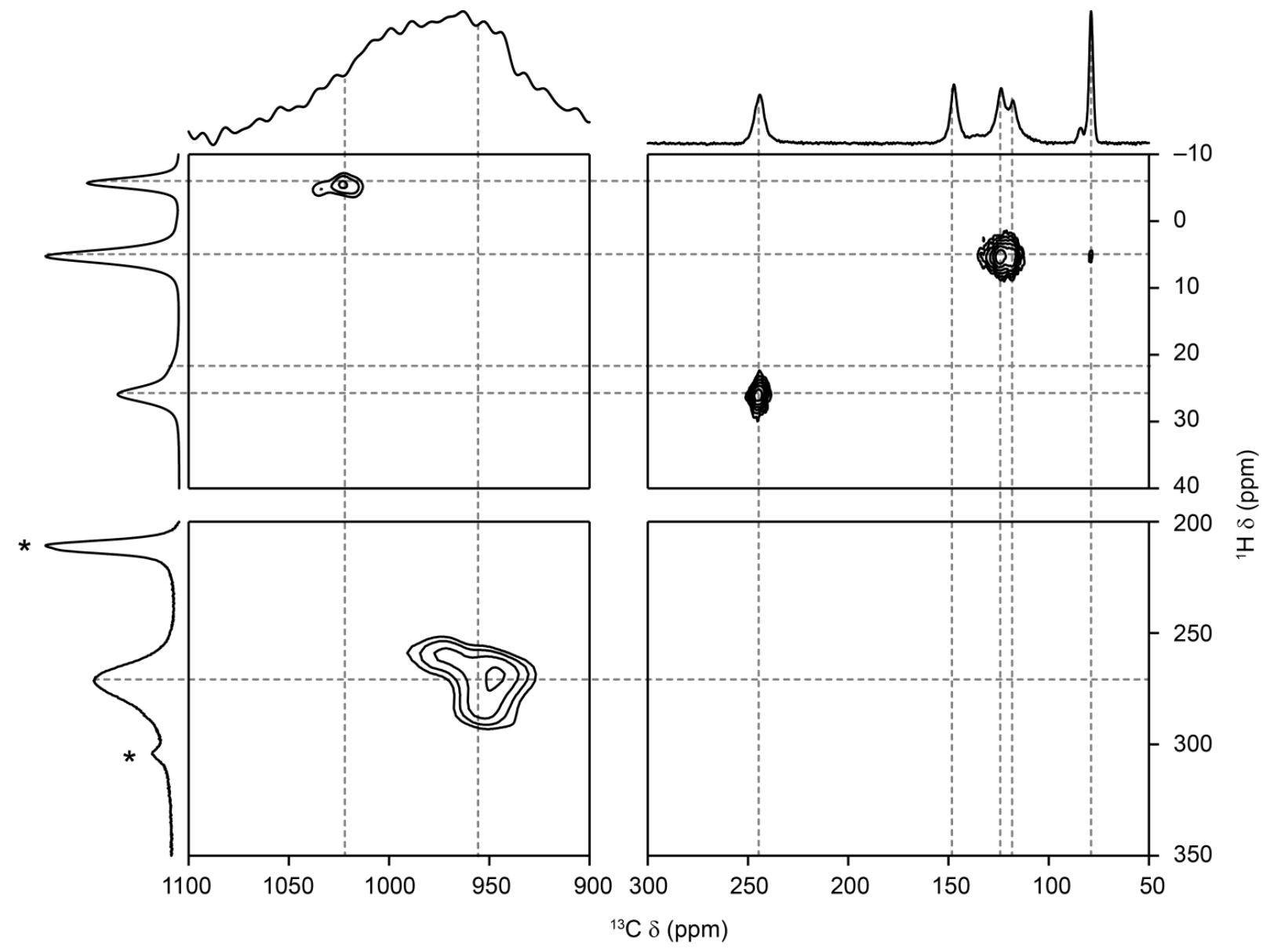

Figure 5. ${ }^{1} \mathrm{H}-{ }^{13} \mathrm{C}(9.4 \mathrm{~T}, 298 \mathrm{~K}, 37.5 \mathrm{kHz}$ CP MAS) HETCOR spectrum of 1 with a contact time of $100 \mu \mathrm{s}$ (the spectrum was recorded in four sections to allow efficient spin locking at all ${ }^{1} \mathrm{H}$ and ${ }^{13} \mathrm{C}$ offset frequencies). The ${ }^{1} \mathrm{H}$ and ${ }^{13} \mathrm{C}$ MAS NMR spectra (recorded at $298 \mathrm{~K}$ ) are shown along the respective axes. Dotted grey lines indicate isotropic peak positions. No resonances were observed in the spectrum shown on the lower right panel. The contour levels in each panel are arbitrary and not to the same scale. 
A second HETCOR spectrum was recorded with a longer contact time (750 $\mu \mathrm{s})$ and is shown in Figure S4 (note that only the region shown in the top right panel of Figure 5 was recorded with the longer contact time). This spectrum shows additional resonances corresponding to $\mathrm{C} 5-\mathrm{H} 3 / 4$ (most likely $\mathrm{H} 4$, owing to its closer proximity to $\mathrm{C} 5$ ), $\mathrm{C} 5-\mathrm{H} 6$ (the same distance as $\mathrm{C} 5-\mathrm{H} 4), \mathrm{C} 1-\mathrm{H} 6$ and $\mathrm{C} 2-\mathrm{H} 6$. However, most importantly, there is no correlation observed at $(148,5.5) \mathrm{ppm}$, suggesting that the corresponding $\mathrm{C}$ species is spatially distant from $\mathrm{H} 3$ and $\mathrm{H} 4$, and should, therefore, indeed be $\mathrm{C} 1$, rather than $\mathrm{C} 2$. On the other hand, there is also no cross-peak observed at either $(118,26.0)$ or $(124,26.0)$ ppm, (expected for C4-H5, due to a very short intramolecular C-H distance of $2.09 \AA$, Table S5), and the peaks at $(148,-5.4)$ and $(79,-5.4)$ involving $\mathrm{H} 6$ are of similar intensity, even though one must be a coupling through two bonds and the other through three. The absence of a cross-peak may, thus, not always be unequivocal for the assignments, and the purely experimental assignment of the ${ }^{13} \mathrm{C}$ resonances for $\mathrm{C} 1$ and $\mathrm{C} 2$ remains tentative. However, in view of the resulting excellent agreement between theory and experiment, it is preferable to assign the ${ }^{13} \mathrm{C}$ resonances at 79 and $148 \mathrm{ppm}$ to $\mathrm{C} 2$ and $\mathrm{C} 1$, respectively. This is not only in agreement with the isotropic shifts, but also their temperature dependence (compare the $\mathrm{d} \delta_{\text {iso }} / \mathrm{d}_{\mathrm{T}}$ entries in Tables 2 and 6$){ }^{33}$

Table 7 gives the final assignment of the resonances, combining information from the solidstate NMR experiments and DFT results. The final estimates were obtained adding the computed packing effect upon trimer formation (the difference between the first and last data entries in Table 4) to the PBE0-1/3/III values in Table 3. At this stage, the only resonances that cannot be conclusively assigned by experiment or calculation are C3 and C4 at 118 and $124 \mathrm{ppm}$. It can be seen that, in general, the difference between the DFT and experimental shifts is, at most, on the order of $10 \%$ of the shift range considered. It should be noted that, while the ${ }^{1} \mathrm{H}$ shift anisotropy values were not necessary for the final assignment, the experimental and calculated values quoted in Tables 1 and 3 are generally in very good agreement (particularly given the large errors on the experimental values and the neglect of longer-range crystal packing effects in the calculations).

Table 7. Comparison of experimental and calculated isotropic shifts (in ppm) at $298 \mathrm{~K}$. For estimated errors in the experimental values, see Tables 1 and 2.

\begin{tabular}{cccc}
\hline Species & exp. $\delta_{\text {iso }}$ & $\begin{array}{c}\text { DFT } \delta_{\text {iso }} \\
\text { (final estimate) }^{a}\end{array}$ & $\begin{array}{c}\text { difference } \\
\text { DFT } \delta_{\text {iso }}-\text { exp. } \delta_{\text {iso }}\end{array}$ \\
\hline H3 & 5.5 & 13.7 & +8.2 \\
H4 & 5.5 & 6.3 & +0.8 \\
H5 & 26.0 & 34.6 & +8.6 \\
H6 & -5.4 & -6.9 & -1.5 \\
H7 & 272 & 293.0 & +21.1 \\
Hbr & 22.7 & 35.5 & +12.8 \\
C1 & 79 & 74.9 & -4 \\
C2 & 148 & 148.0 & \pm 0 \\
C3/C4 & 124,118 & $111.3,150.7$ & -13 to +33 \\
C5 & 244 & 223.4 & -21 \\
C6 & 1006 & 1126.3 & +120 \\
C7 & 963 & 894.7 & -68 \\
\hline
\end{tabular}

a Obtained by adding the computed packing effects at the PBE0-1/3/II level to the PBE0 $-1 / 3 /$ III data (see text). 
Despite its spatial proximity to the $\mathrm{Cu}$ centre, the bridging $\mathrm{H}$ atom does not show the largest isotropic paramagnetic shift; 34 it does show, however, the largest anisotropy by far (Tables 1 and 6 ), indicating that the shielding and deshielding effects in the principal components cancel to a large extent in the isotropic shift. The ability to calculate accurately the shift anisotropy may prove useful in assigning the NMR spectra of other paramagnetic solids, where resonances may have similar isotropic shifts but different anisotropies (e.g., $\mathrm{H} 5$ and $\mathrm{H}(\mathrm{br})$ in 1 have an isotropic shift difference of just $3 \mathrm{ppm}$, but a difference in $\Omega$ of over 200 ppm).

\section{Substituent Effects}

A variety of derivatives of complex 1 can be synthesised and those shown in Chart 1 were chosen for initial theoretical investigation of the effects of the substituents on the NMR and EPR parameters. The substituent effects were probed computationally for the pristine monomeric complexes (PBE0-1/3/ IGLO-II level) and the results are summarised in Table 8.

\section{Chart 1}

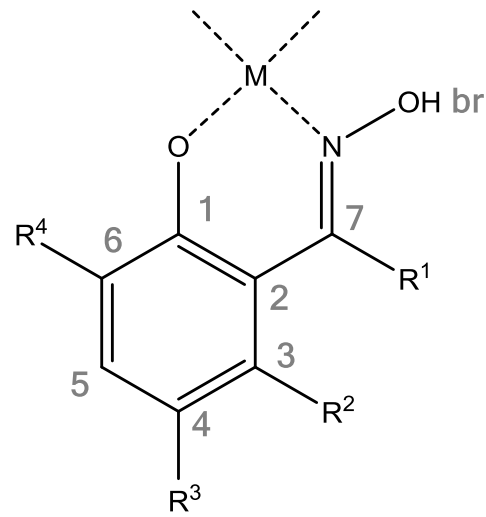

\begin{tabular}{c|ccccl} 
& $\mathbf{1}$ & $\mathbf{2}$ & $\mathbf{3}$ & $\mathbf{4}$ & $\mathbf{5}$ \\
\hline $\mathrm{R}^{1}$ & $\mathrm{H}$ & $\mathrm{Me}$ & $\mathrm{H}$ & $\mathrm{H}$ & $\mathrm{H}$ \\
$\mathrm{R}^{2}$ & $\mathrm{H}$ & $\mathrm{H}$ & $\overbrace{}^{8}$ & $\mathrm{H}$ & $\mathrm{H}$ \\
$\mathrm{R}^{3}$ & $\mathrm{H}$ & $\mathrm{H}$ & $\mathrm{J}_{10}$ & $\mathrm{H}$ & $\mathrm{tBu}$ \\
$\mathrm{R}^{4}$ & $\mathrm{H}$ & $\mathrm{H}$ & $\mathrm{H}$ & $\mathrm{OMe}$ & $\mathrm{H}$
\end{tabular}

Table 8: Substituent effects on monomeric salicylaldoxime-Cu(II) complexes, PBE0-1/3/ IGLO-II level (labelling as in Chart 1).

\begin{tabular}{rrrrrrrrrrrr}
\hline & $\mathrm{H} 3$ & $\mathrm{H} 4$ & $\mathrm{H} 5$ & $\mathrm{H} 6$ & $\mathrm{H} 7$ & $\mathrm{H}(\mathrm{br})$ & $\mathrm{H}(\mathrm{R})^{a}$ & $\mathrm{H} 9$ & $\mathrm{H} 10$ & $\mathrm{H} 11$ & \\
\hline $\mathbf{1}$ & 13.4 & 6.5 & 35.0 & -6.8 & 306.6 & 31.7 & - & & & & \\
$\mathbf{2}$ & 15.1 & 6.7 & 35.2 & -3.7 & - & 28.2 & -29.0 & & & & \\
$\mathbf{3}$ & - & - & 43.0 & -8.2 & 303.7 & 33.5 & 8.0 & 10.5 & 7.0 & 9.4 & \\
$\mathbf{4}$ & 12.3 & 5.0 & 40.2 & - & 308.6 & 32.0 & 4.0 & & & & \\
$\mathbf{5}$ & 13.2 & - & 35.0 & -7.7 & 306.5 & 31.5 & 1.1 & & & & \\
\hline \multicolumn{1}{c}{$\mathrm{C} 1$} & $\mathrm{C} 2$ & $\mathrm{C} 3$ & $\mathrm{C} 4$ & $\mathrm{C} 5$ & $\mathrm{C} 6$ & $\mathrm{C} 7$ & $\mathrm{C}(\mathrm{R})^{a}$ & $\mathrm{C} 9$ & $\mathrm{C} 10$ & $\mathrm{C} 11$ \\
\hline $\mathbf{1}$ & 79.2 & 132.4 & 108.8 & 144.8 & 235.3 & 1167 & 931.4 & - & & & \\
$\mathbf{2}$ & 84.6 & 120.2 & 77.4 & 136.7 & 270.4 & 1146 & 951.4 & 458.9 & & & \\
$\mathbf{3}$ & 138.2 & 122.6 & 86.1 & 156.1 & 266.8 & 1209 & 932.4 & 142.5 & 120.0 & 142.5 & 127.5 \\
$\mathbf{4}$ & 175.9 & 131.2 & 99.9 & 149.3 & 163.8 & 1059 & 919.2 & 47.4 & & & \\
$\mathbf{5}$ & 70.5 & 130.0 & 102.4 & 168.0 & 229.6 & 1174 & 946.9 & $35.5^{b}$ & & & \\
\hline
\end{tabular}


A more detailed NMR spectroscopic investigation of these derivatives will be published elsewhere ${ }^{35}$ but, here, we offer the following general assessments of the computed values. The isotropic ${ }^{1} \mathrm{H}$ shifts are not very sensitive to the substituent patterns explored here: the strongly deshielded $\mathrm{H} 7$ remains close to $300 \mathrm{ppm}$ and $\mathrm{H} 6$ is always slightly shielded, leading to a very similar shift range in all cases. It can be seen from the predicted shifts for $\mathbf{3}$ that the presence of the unpaired spin is not expected to significantly affect the second ring of the naphthalene moiety, as perhaps expected given that the hyperfine coupling relies on the $s$ character of the $\sigma$ bonds, rather than being transferred through the $\pi$ orbitals.

In comparison to the ${ }^{1} \mathrm{H}$ resonances, some of the ${ }^{13} \mathrm{C}$ isotropic shifts are much more sensitive to the substituents. Most notably, the $\delta$ values for $\mathrm{C} 1$ and $\mathrm{C} 5$, whose substituents remain unchanged, show the largest variations across the series, up to $100 \mathrm{ppm}$. In some cases a complete change of the sequence of the signals can ensue (compare, e.g., data for 1 and 4 in Table 8). Among the most deshielded resonances computed for $\mathrm{C} 6$ and $\mathrm{C} 7$, the shift of C6 is the most sensitive, varying by up to $150 \mathrm{ppm}$ (compare values for $\mathbf{3}$ and $\mathbf{4}$ in Table 8). Qualitatively, however, this region of the spectrum should remain much the same across the whole series (although the two resonances may overlap, depending on linewidth). For 2 , the calculation that the methyl carbon should be strongly deshielded ( $\delta=458.9 \mathrm{ppm})$ is confirmation that the spin density is very high on the imido moiety, .

\section{Conclusions}

In summary, we have recorded and analysed the solid-state ${ }^{1} \mathrm{H}$ and ${ }^{13} \mathrm{C}$ NMR spectra of the bis(salicylaldoximato)copper (II) complex 1. First-principles computation of the salient NMR parameters, mainly isotropic shifts and their temperature dependence, were instrumental for the assignment of the signals. Near-complete assignment was possible with additional twodimensional heteronuclear correlation spectra.

Computationally, we have studied intermolecular effects on the pNMR shifts in small cluster models as a first step toward modelling a molecular crystal consisting of weakly-interacting paramagnetic molecules. This is achieved through effective decoupling between the local spins, justified by the essentially vanishing exchange coupling between them. Judging from these results, such intermolecular effects on the pNMR shifts are relatively small. For the $\mathrm{Cu}$ complexes in this study, these effects are dwarfed by the intricacies of the electronic structure of the monomeric units, which are reflected, e.g., in the large dependencies of the computed pNMR shifts on the exchange-correlation functional. Commensurate with previous experience, ${ }^{36}$ a high fraction of Hartree-Fock exchange (33\% in the present case) is beneficial for this purpose. The computational investigation was then extended to predict the NMR parameters of a series of complexes with substituted oximate ligands.

Analysis of the computed shielding tensors confirms the expectation that the isotropic pNMR shifts are governed by the contact shifts, essentially probing the isotropic (Fermi-contact) part of the hyperfine coupling at the nucleus in question. For ${ }^{13} \mathrm{C}$ nuclei in particular, pNMR spectroscopy can thus be an important complement to EPR spectroscopy, where such couplings can be difficult to assign at natural abundance. In conjunction with theory, the pNMR spectra afford exquisitely detailed insights into the spin distribution within these metal complexes and into the way this spin distribution can be modulated through substituents 
attached to the organic ligands. More work will be needed to establish relationships between these spin distributions, molecular and crystal structures, and properties of potential interest for technological applications such as metal-ligand binding affinities or solubilities of the complexes.

Neither pNMR measurements nor computational modeling of solid materials are routine tasks at present. Challenges for further work abound, namely to find the appropriate conditions to record the spectra (e.g., spinning speed, temperature control) and to find the appropriate quantum-chemical tools to assign and interpret them. On the theoretical side, the challenges comprise the accurate modeling of effects from the bulk solid (most efficiently through inclusion of periodic boundary conditions), and probably thermal and zero-point corrections; all compounded by the huge sensitivity of the results to the theoretical level (i.e., the exchange-correlation functional if DFT is used). Few of these challenges appear insurmountable already, so that further work in this area may be rewarding.

\section{Experimental Section}

\section{Synthesis}

Salicylaldoxime. Salicylaldehyde $(1.83 \mathrm{~g} 15 \mathrm{mmol})$ in $80 \%$ aqueous ethanol $\left(40 \mathrm{~cm}^{3}\right)$ was added to a solution of hydroxylamine hydrochloride $(2.08 \mathrm{~g}, 30 \mathrm{mmol})$ and sodium acetate $(3.04 \mathrm{~g}, 37 \mathrm{mmol})$ in deionised water $\left(10 \mathrm{~cm}^{3}\right)$ and the solution was stirred at room temperature for $3 \mathrm{~h}$. The solvent was removed in vacuo and deionised water $\left(20 \mathrm{~cm}^{3}\right)$ was added to the crude residue. The product was extracted using ethyl acetate $\left(3 \times 20 \mathrm{~cm}^{3}\right)$ and the three organic fractions were combined and washed with brine $\left(3 \times 15 \mathrm{~cm}^{3}\right)$. The organic layers were dried over anhydrous sodium sulfate and the solvent was removed in vacuo. The crude product was recrystallized from boiling $60-80$ petroleum ether $(20 \mathrm{ml})$ to afford white crystals of salicylaldoxime (1.06 g, $7.73 \mathrm{mmol}\left(51.5 \%\right.$ yield) m.p. $\left.56.2-58.3^{\circ} \mathrm{C}\right) .{ }^{1} \mathrm{H}$ $\operatorname{NMR}\left(400.13 \mathrm{MHz}, \mathrm{CDCl}_{3}, \mathrm{Me}_{4} \mathrm{Si}\right) \delta(\mathrm{ppm}): 9.79(1 \mathrm{H}, \mathrm{s}, \mathrm{C}-\mathrm{OH}), 8.24(1 \mathrm{H}, \mathrm{t}, \mathrm{J}=0.4 \mathrm{~Hz}, \mathrm{H} 7)$, $7.30(1 \mathrm{H}, \mathrm{s}, \mathrm{N}-\mathrm{OH}), 7.29(1 \mathrm{H}$, ddd, J = 8.3, 7.3, $1.7 \mathrm{~Hz}, \mathrm{H} 5), 7.19(1 \mathrm{H}$, ddt, J = 7.7, 1.7, 0.4 $\mathrm{Hz}, \mathrm{H} 3), 6.99(1 \mathrm{H}, \mathrm{ddt}, \mathrm{J}=8.3,1.2,0.4 \mathrm{~Hz}, \mathrm{H6}), 6.93(1 \mathrm{H}, \mathrm{ddd}, \mathrm{J}=7.5,7.4,1.2 \mathrm{~Hz}, \mathrm{H} 4) .{ }^{13} \mathrm{C}$ $\left\{{ }^{1} \mathrm{H}\right\}$ NMR: (100.66 MHz, CDCl $\left.3, \mathrm{Me}_{4} \mathrm{Si}\right) \delta$ (ppm): 157.3 (C1), 153.2 (C7), 131.5 (C5), 130.9 (C3), 119.9 (C4), 116.9 (C6) and 116.4 (C2).

Bis(salicylaldoximato)copper(II). Salicylaldoxime $(0.14 \mathrm{~g}, 1 \mathrm{mmol})$ in absolute ethanol (12 $\mathrm{cm}^{3}$ ) was added to a hot solution of $0.02 \mathrm{M}$ aqueous copper(II) sulfate $\left(25 \mathrm{~cm}^{3}\right)$. The mixture was stirred for 15 minutes and filtered under suction to afford a pale brown precipitate, which was washed with deionised water ( $80 \mathrm{mg}, 47 \%$ yield).

\section{NMR Spectroscopy}

Solution-state NMR spectra were recorded using a Bruker Avance II spectrometer, equipped with a 9.4 T superconducting magnet $\left({ }^{1} \mathrm{H}\right.$ and ${ }^{13} \mathrm{C}$ Larmor frequencies of 400.13 and 100.66 $\mathrm{MHz}$, respectively). Chemical shifts are quoted relative to $\left(\mathrm{CH}_{3}\right)_{4} \mathrm{Si}$, using the residual $\mathrm{CHCl}_{3}$ and $\mathrm{CDCl}_{3}$ solvent peaks (7.26 and 77.16 ppm, respectively). 
Solid-state NMR spectra were recorded using a Bruker Avance III spectrometer, equipped with a 9.4 T wide-bore superconducting magnet $\left({ }^{1} \mathrm{H}\right.$ and ${ }^{13} \mathrm{C}$ Larmor frequencies of 400.13 and $100.66 \mathrm{MHz}$, respectively). Experiments were carried out using a $1.9 \mathrm{~mm}$ MAS probe, with MAS rates between 16 and $37.5 \mathrm{kHz} .{ }^{1} \mathrm{H}$ and ${ }^{13} \mathrm{C}$ chemical shifts are quoted relative to $\left(\mathrm{CH}_{3}\right)_{4} \mathrm{Si}$, using the $\mathrm{NH}_{3}$ and $\mathrm{CH}_{3}$ resonances of L-alanine (8.5 and $20.5 \mathrm{ppm}$, respectively) as secondary references. MAS spectra were recorded using a rotor-synchronised spin-echo pulse sequence with an echo delay of one rotor period. Signal averaging was carried out for $512\left({ }^{1} \mathrm{H}\right)$ or $81920-448512$ transients $\left({ }^{13} \mathrm{C}\right)$ with a recycle interval of $100 \mathrm{~ms}$ in all cases. The magnitude of the chemical shift anisotropy is defined by the span $\left(\Omega=\delta_{11}-\delta_{33}\right)$, where the three principal components of the diagonalised shift tensor are ordered with $\delta_{11} \geq \delta_{22} \geq \delta_{33}$ and $\delta_{\text {iso }}=\left(\delta_{11}+\delta_{22}+\delta_{33}\right) / 3$. The HETCOR spectra were recorded using CP from ${ }^{1} \mathrm{H}$ with a contact pulse (ramped for ${ }^{1} \mathrm{H}$ ) of 100 or $750 \mu \mathrm{s}$, and are the result of averaging between 440 and 32768 transients for each of between 14 and $80 t_{1}$ increments of 12.5 to $26.67 \mu \mathrm{s}$, with a interval of $100 \mathrm{~ms}$. The sample temperature was controlled using a Bruker BCU-II chiller and Bruker BVT/BVTB-3000 temperature controller and heater booster. The sample temperature (including frictional heating effects arising from sample spinning) was calibrated using the isotropic ${ }^{87} \mathrm{Rb}$ shift of solid $\mathrm{RbCl} .{ }^{37}$

\section{Computational Details}

Structures were optimised with the Gaussian 09 program $^{38}$ at RI-BP86, ${ }^{39}$ PBE0 ${ }^{40,41}$ and PBE0-D3 ${ }^{42,43}$ levels of density functional theory, employing the $A E 1^{(*)}$ basis, i.e., a Wachters basis ${ }^{44}$ augmented with two diffuse $p$ and one diffuse $d$ sets for $\mathrm{Cu}(8 \mathrm{~s} 7 \mathrm{p} 4 \mathrm{~d}$, full contraction scheme $62111111 / 3311111 / 3111), 6-31 \mathrm{G}^{* * 45}$ for the $\mathrm{H}(\mathrm{br})$ atoms and $6-31 \mathrm{G}^{*}$ for all other atoms. The $\sigma_{\text {orb }}, g$ and $A$ tensors were computed at the PBE, ${ }^{40}$ PBE0 and PBE0 $-1 / 3^{46}$ levels using 9s7p4d basis sets on 3d metals that were constructed specifically for hyperfine coupling constant calculations (full contraction scheme 621111111/3311111/3111), ${ }^{47}$ and the IGLO-II or IGLO-III basis ${ }^{48}$ on the ligands. The $\sigma_{\text {orb }}$ calculations employed gauge-including atomic orbitals and fine integration grids as implemented in Gaussian 09; $g$ and $A$ tensors were computed with the ORCA program ${ }^{49}$ (tight SCF convergence and fine integration grid, Grid5 option). Unless otherwise noted, all NMR and EPR properties were computed using the same functional/basis-set combinations.

Magnetic shielding tensors $\sigma$ were computed using the formalism according to reference 14 . Here we only consider the isotropic average,

$$
\sigma_{\text {iso }}=\sigma_{\text {iso(orb })}-\mathrm{S}(\mathrm{S}+1) \beta_{\mathrm{e}} /\left(3 k \operatorname{Tg} N \beta_{\mathrm{N}}\right)\left[g_{\mathrm{e}} \cdot A_{\mathrm{FC}}+g_{\mathrm{e}} \cdot A_{\mathrm{PC}}+\Delta g_{\mathrm{iso}} \cdot A_{\mathrm{FC}}+1 / 3 \operatorname{Tr}\left(\Delta \mathbf{g}_{\text {aniso }} \cdot \mathbf{A}_{\text {dip }}\right)\right] \text {, }
$$

where $\sigma_{\text {iso(orb) }}$ is the isotropic orbital shielding, $S$ is the effective spin, $\beta_{\mathrm{e}}$ and $\beta_{\mathrm{N}}$ are Bohr magneton and nuclear magneton, respectively, $T$ is the temperature (set to $298.15 \mathrm{~K}$ ), $g_{\mathrm{e}}$ and $g_{N}$ are the free-electron and nuclear $g$-values, respectively, $A_{\mathrm{FC}}$ and $\mathbf{A}_{\text {dip }}$ are the usual isotropic Fermi-contact and anisotropic traceless spin-dipolar contribution to the A-tensor, respectively, $A_{\mathrm{PC}}$ the isotropic pseudo-contact (PC) term arising from spin-orbit corrections to the $A$-tensor, and $\Delta g_{\text {iso }}$ and $\Delta g_{\text {aniso }}$ are the isotropic and anisotropic parts of the g-tensor, respectively (in the usual representation of the g-tensor in the form $\mathbf{g}=g_{\mathrm{e}}+\Delta g_{\text {iso }} \cdot \mathbf{1}+\Delta \mathbf{g}_{\text {iso }}$ ). Chemical shifts $\delta$ are reported relative to TMS according to 
$\delta=\sigma_{\text {iso(orb) }}\left(\right.$ TMS) $-\sigma_{\text {iso(orb) }}$

where the isotropic orbital shieldings of TMS have been computed at the same level (see Table S4 for individual values).

Acknowledgments. We thank Arobendo Mondal for helpful discussions. This work was supported by EaStCHEM and the School of Chemistry. Computations were performed on local computer clusters maintained by Dr. Herbert Früchtl. We would like to thank the EPSRC for computational support through the Collaborative Computational Project on NMR Crystallography (CCP-NC), via EP/M022501/1 and EP/J501542/1. SEA would like to thank the Royal Society and Wolfson Foundation for a merit award. Work at the TU Berlin has been carried out within the EU Marie-Curie Initial Training Network "pNMR". For access to research data and metadata see DOI: 10.17630/XXX.

\section{References}

1 F. Habashi, Hydrometallurgy 2005, 79, 15-22.

2 M. A. Wilson, P. J. Bailey, P. A. Tasker, J. R. Turkington, R. A. Grant, J. B. Love, Chem. Soc. Rev. 2014, 43, 123-134.

3 I. A. Smellie, R. S. Forgan, C. Brodie, J. S. Gavine, L. Harris, D. Houston, A. D. Hoyland, R. P. McCaughan, A. J. Miller, L. Wilson, F. M. Woodhall, J. Chem. Educ. 2016, 93, 362367.

4 About half of the more than 120 transition-metal phenolic bis(oxime) complexes deposited in the Cambridge Structure Database (Version 5.37, November 2015) contain Cu(II) as metal centre, see e.g.: A. G. Smith, P. A. Tasker, D. J. White, Coord. Chem. Rev. 2003, 241, 61-85.

5 (a) A. M. Whyte, B. Roach, D. K. Henderson, P. A. Tasker, M. M. Matsushita, K. Awaga, F. J. White, P. Richardson, N. Robertson, Inorg. Chem. 2011, 50, 12867-12876; frozen solution: (b) M. R. Healy, E. Carter, I. A. Fallis, R. S. Forgan, R. J. Gordon, E. Kamenetzky, J. B. Love, C. A. Morrison, D. M. Murph, P. A. Tasker, Inorg. Chem. 2015, 54, 8465-8473.

6 I. Bertini, L. Emsley, M. Lelli, C. Luchinat, J. Mao, G. Pintacuda, J. Am. Chem. Soc. 2010, 132, 5558-5558.

7 N. P. Wickramasinghe, Y. Ishii, J. Magn. Reson. 2006, 181, 233-243.

8 (a) G. de Combarieu, M. Morcrette, F. Millange, N. Guillou, J. Cabana, C. P. Grey, I. Margiolaki, G. Férey, J. M. Tarascon, Chem. Mater., 2009, 21, 1602-1611; (b) D. M. Dawson, L. E. Jamieson, M. I. H. Mohideen, A. C. McKinlay, I. A. Smellie, R. Cadou, N. S. Keddie, R. E. Morris, S. E. Ashbrook, Phys. Chem. Chem. Phys. 2013,15, 919-929.

9 J. Kim, D. S. Middlemiss, N. A. Chernova, B. Y. X. Zhu, C. Masquelier, C. P. Grey, J. Am. Chem. Soc., 2010, 132, 16825-16840.

10 See, e.g.: M. Kaupp, M. Bühl, V. G. Malkin (Eds.), Calculation of NMR and EPR Parameters. Theory and Applications, Wiley-VCH, Weinheim, 2004.

11 For some overviews in the context of solid-state NMR see e.g.: (a) C. Bonhomme, C. Gervais, F. Babonneau, C. Coelho, F. Pourpoint, T. Azaïs, S. E. Ashbrook, J. M. Griffin, J. R. Yates, F. Mauri, C. J. Pickard, Chem. Rev. 2012, 112, 5733-5779; (b) S. E. Ashbrook, D. McKay, Chem. Commun. 2016, 52, 7186-7204.

12 Z. Rinkevicius, J. Vaara, L. Telyatnyk, O. Vahtras, J. Chem. Phys. 2003, 118, 2550-2561.

13 S. Moon, S. Patchkovskii, in: Calculation of NMR and EPR Parameters. Theory and Applications, M. Kaupp, M. Bühl, V. G. Malkin (Eds.), Wiley-VCH, Weinheim, 2004, pp. 325-340. 
14 P. Hrobarik, R. Reviakine, A. V. Arbuznikov, O. L. Malkina, V. G. Malkin, F. Koehler, M. Kaupp. J. Chem. Phys. 2007, 126, 024107.

15 (a) T. O. Pennannen, J. Vaara, J. Chem. Phys. 2005, 123, 174102; (b) T. O. Pennannen, J. Vaara, Phys. Rev. Lett. 2008, 100, 133002; (b) S. A. Rouf, J. Mareš, J. Vaara, J. Chem. Theory Comput. 2015, 11, 1683-1691.

16 B. Martin, J. Autschbach, J. Chem. Phys. 2015, 142, 054108.

17 (a) W. Van den Heuvel, A. Soncini, Phys. Rev. Lett. 2012, 109, 073001; (b) W. Van den Heuvel, A. Soncini, J. Chem. Phys. 2013, 138, 054113

18 Although some such calculations have been proposed for undergraduate computational chemistry "experiments": B. P. Pritchard, S. Simpson, E. Zurek, J. Autschbach, J. Chem. Educ. 2014, 91, 1058-1063.

19 E.g.: (a) D. Carlier, M. Menetrier, C. P. Grey, C. Delmas, G. Ceder, Phys. Rev. B 2003, 67, 174103; (b) D. S. Middlemiss, A. J. Ilott, R. J. Clément, F. C. Strobridge, C. P. Grey, Chem. Mater. 2013, 25, 1723-1734.

20 CSD refcode SALCOP: M. A. Jarski, E. C. Lingafelter, Acta. Crystallogr. 1964, 19, 11091112

21 E.g., CSD refcode SALCOP03: K. N. Lazarou, A. K. Boudalis, V. Psycharis, C. P. Raptopoulou, Inorg. Chimica Acta 2011, 370, 50-58.

22 The PBE0 level performs very well for metal-ligand bond distances in transition-metal complexes (M. Bühl, C. Reimann, D. A. Pantazis, T. Bredow, F. Neese, J. Chem. Theory Comput. 2008, 4, 1449-1459), and the dispersion correction is instrumental for describing intermolecular interactions, as in the oligomers that have been considered here.

23 The shortest distance between the perpendicularly oriented stacks is between $\mathrm{H} 6$ in one stack and the phenolic $\mathrm{O}$ atom in the other ( $\mathrm{C} \cdots \mathrm{O}$ distance $3.40 \AA$ ), implying a weak $\mathrm{CH} \cdots \mathrm{O}$ hydrogen bond.

24 This procedure was adopted (rather than extracting sections from the experimental crystal structure directly), because optimised structures tend to perform better in NMR chemical shift calculations than raw X-ray derived coordinates (see e.g.: S. E. Ashbrook, M. E. Cutajar, C. J. Pickard, R. I. Walton, S. Wimperis, Phys. Chem. Chem. Phys. 2008, 10, 5754-5764).

25 Depending on the substituent pattern, both ferromagnetic and antiferromagnetic behaviour has been reported for phenolic oxime Cu complexes, cf. reference $5 \mathrm{a}$.

26 See, e.g.: (a) Y. Ruiz-Morales, G. Schreckenbach, T. Ziegler, Organometallics 1996, 15, 3920-3923; sometimes spin-orbit-effects can be overriding: (b) P. Hrobarik, V. Hrobarikova, F. Meier, M. Repisky, S. Komorovsky, M. Kaupp, J. Phys. Chem. A 2011, 115, 5654-5659; (c) P. Hrobarik, V. Hrobarikova, A. H. Greif, M. Kaupp, Angew. Chem. Int. Ed. 2012, 51, 10884-10888.

27 These $\sigma_{\text {orb }}$ values (PBE0-1/3/ II level, data not shown) are essentially the same for paramagnetic 1 and a diamagnetic variant where $\mathrm{Cu}$ has been replaced with $\mathrm{Zn}$, indicating that anisotropy effects from the paramagnetic metal centre are negligible in our case.

28 The D-tensor calculations did not converge at the PBE0-1/3 level; for the dimer the results for the D-tensor obtained at the PBE/IGLO-II level (where the computed D-value is 17.4 $\mathrm{cm}^{-1}$ ) where used along with the remaining quantities obtained at the PBE0-1/3/IGLO-II level.

29 See, e.g.: M. Munzarova, in: Calculation of NMR and EPR Parameters. Theory and Applications, M. Kaupp, M. Bühl, V. G. Malkin (Eds.), Wiley-VCH, Weinheim, 2004, pp. 463-482.

30 When applied to truly uncoupled systems with single unpaired electrons, as for instance two methyl radicals $1000 \AA$ away of each other, where the full system treated as a triplet, this procedure recovers the results for a monomeric doublet.

31 Very similar results are obtained for the other possible doublet state, where the spin on the other terminal metal fragment has been flipped in addition, i.e., " $\downarrow \uparrow \downarrow "$ (the resulting 
pNMR shifts are within $0.2 \mathrm{ppm}$ of those for the "BS $\downarrow \uparrow \uparrow "$ state in Table S3, data not shown).

32 This value is irrespective of the particular approximation for the spin-Hamiltonian analysis, which uses the energy difference and information from the total spin and/or the expectation values of the $\hat{S}^{2}$ operator: (a) A. P. Ginsberg, J. Am. Chem. Soc. 1980, 102, 111; (b) L. Noodleman, E. R. Davidson, Chem. Phys. 1985, 109, 131; (c) T. Soda,Y. Kitagawa, T. Onishi, Y. Takano, Y. Shigeta, H. Nagao, Y. Yoshioka, K. Yamaguchi, , Chem. Phys. Lett. 2000, 319, 223-230.

33 The computed infinite-temperature limits are also consistent with this assignment: For $\mathrm{C} 1$ and $\mathrm{C} 2, \delta_{\text {iso }}^{\infty}=169.6$ and $119.1 \mathrm{ppm}$, respectively, are obtained (Table 6), in very good agreement with the observed resonances in the diamagnetic $\mathrm{Ni}^{2+}$ analogue (158.9 and 116.4 ppm, respectively, D. M. Dawson, R. A. Doyle and S. E. Ashbrook, unpublished work). The corresponding experimental values in Table 2 are not conclusive in that respect, because they contain the thermal effects on $\delta_{\text {orb }}$ on top and are associated with some uncertainty from the long-range extrapolation to $1 / T \rightarrow 0$ ).

34 The chemical shift predicted from the $\sigma_{\text {iso(orb) }}$ part of monomeric $1, \delta=11.2 \mathrm{ppm}$, is similar to that in other diamagnetic complexes, where the resonances of these bridging protons have been observed, e.g., at $\delta=10.9 \mathrm{ppm}$ for the $\mathrm{Pt}$ (II) complex in $\mathrm{CCl}_{4}$ solution (S. F. Kaplan, V. Y. Kukushkin, S. Shova, K. Suwinska, G. Wagner, A. J. L. Pombeiro, Eur. J. Inorg. Chem. 2001, 1031-1038).

35 R. A. Doyle, D. M. Dawson, I. A. Smellie, M. Bühl, D. B. Cordes, A. M. Z. Slawin, S. E. Ashbrook, Manuscript in Preparation.

36 E.g., for organic mixed-valence radicals: (a) M. Renz, K. Theilacker, C. Lambert, M. Kaupp, J. Am. Chem. Soc. 2009, 131, 16292-16302; (b) M. Renz, M. Kess, M. Diedenhofen, A. Klamt, M. Kaupp, J. Chem. Theory Comput. 2012, 8, 4189-4203.

37 J. Skibsted, H. J. Jakobsen, J. Phys. Chem. A, 1999, 103, 7958-7971.

38 M. J. Frisch, G. W. Trucks, H. B. Schlegel, G. E. Scuseria, M. A. Robb, J. R. Cheeseman, G. Scalmani, V. Barone, B. Mennucci, G. A. Petersson, H. Nakatsuji, M. Caricato, X. Li, H. P. Hratchian, A. F. Izmaylov, J. Bloino, G. Zheng, J. L. Sonnenberg, M. Hada, M. Ehara, K. Toyota, R. Fukuda, J. Hasegawa, M. Ishida, T. Nakajima, Y. Honda, O. Kitao, H. Nakai, T. Vreven, J. J. A. Montgomery, J. E. Peralta, F. Ogliaro, M. Bearpark, J. J. Heyd, E. Brothers, K. N. Kudin, V. N. Staroverov, T. Keith, R. Kobayashi, J. Normand, K. Raghavachari, A. Rendell, J. C. Burant, S. S. Iyengar, J. Tomasi, M. Cossi, N. Rega, J. M. Millam, M. Klene, J. E. Knox, J. B. Cross, V. Bakken, C. Adamo, J. Jaramillo, R. Gomperts, R. E. Stratmann, O. Yazyev, A. J. Austin, R. Cammi, C. Pomelli, J. W. Ochterski, R. L. Martin, K. Morokuma, V. G. Zakrzewski, G. A. Voth, P. Salvador, J. J. Dannenberg, S. Dapprich, A. D. Daniels, O. Farkas, J. B. Foresman, J. V. Ortiz, J. Cioslowski and D. J. Fox, Gaussian 09, Revision B.01, Gaussian, Inc., Wallingford CT, 2010.

39 (a) A. D. Becke, Phys. Rev. A, 1988, 38, 3098-3100; (b) J. P. Perdew, Phys. Rev. B 1986, 33, 8822-8824; (c) J. P. Perdew, Phys. Rev. B, 1986, 34, 7406.

40 (a) J. P. Perdew, In Electronic Strucure of Solids, Ziesche, P.; Eischrig, H. Eds.: Akademie Verlag: Berlin (1991); (b) J. P. Perdew, Y. Wang, Phys. Rev. B 1992, 45, 13244-13249.

41 (a) J. P. Perdew, M. Ernzerhof, K. Burke, J. Phys. Chem. 1996, 105, 9982-9985; (b) C. Adamo. V. Barone, J. Chem. Phys. 1999, 110, 6158-6170.

42 S. Grimme, J. Antony, S. Ehrlich, H. Krieg, J. Chem. Phys. 2010, 132, 154104.

43 including Becke-Johnson damping: (a) A. D. Becke, E. R. Johnson, J. Chem. Phys. 2005, 122, 154104; (b) E. R. Johnson, A. D. Becke, J. Chem. Phys. 2006, 124, 174104. 44 (a) A. J. H. Wachters, J. Chem. Phys. 1970, 52, 1033-1036; (b) P. J. Hay, J. Chem. Phys. 1977, 66, 4377-4384.

45 (a) W. J. Hehre, R. Ditchfield, J. A. Pople, J. Chem. Phys. 1972, 56, 2257-2261; (b) P. C. Hariharan, J. A. Pople, Theor. Chim. Acta 1973, 28, 213-222.

46 C. A. Guido, E. Bremond, C. Adamo, P. Cortona, J. Chem. Phys. 2001, 138, 201104. 
47 M. Munzarová, M. Kaupp, J. Phys. Chem. A 1999, 103, 9966.

48 W. Kutzelnigg, U. Fleischer, M. Schindler, In: NMR Basic Principles and Progress Vol. 23, Springer-Verlag: Berlin, 1990, p. 165.

49 Orca, Version 3.0.3: (a) F. Neese, WIREs Comp. Mol. Sci 2012, 2, 73-78; (b) https://orcaforum.cec.mpg.de (accessed 20 May 2016). 
NMR With a Spin

M. Bühl, S. E. Ashbrook, D. M. Dawson, R. A. Doyle, $P$.

Hrobarik, M. Kaupp, I. A. Smellie

Paramagnetic NMR of phenolic oxime copper complexes - a joint experimental and density functional study

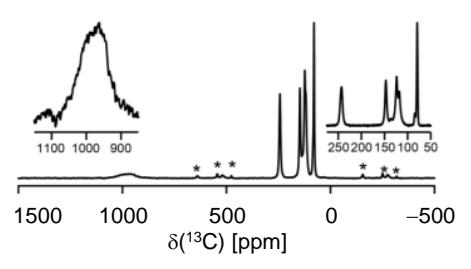

Armed with good-quality DFT calculations, pNMR spectroscopy can give detailed insights into the spin distribution of phenolic oxime copper(II) complexes in the solid, and into the way this can be modulated by

intermolecular and substituent effects. 